\title{
A Bee Colony Optimization (BCO) and Type-2 Fuzzy Approach to Measuring the Impact of Speed Perception on Motor Vehicle Crash Involvement
}

\section{Marjana Čubranić-Dobrodolac}

Univerzitet u Beogradu Saobracajni Fakultet

\section{Libor Švadlenka}

University of Pardubice Faculty of Transport Engineering: Univerzita Pardubice Dopravni Fakulta Jana

Pernera

\section{Svetlana Čičević}

Univerzitet u Beogradu Saobracajni Fakultet

\section{Aleksandar Trifunović}

Univerzitet u Beogradu Saobracajni Fakultet

Momčilo Dobrodolac ( $\nabla$ m.dobrodolac@sf.bg.ac.rs )

Univerzitet u Beogradu Saobracajni Fakultet https://orcid.org/0000-0001-8112-8329

\section{Research Article}

Keywords: oad safety, motor vehicle crashes, speed perception, fuzzy inference system, bee colony optimization, metaheuristic optimization

Posted Date: May 18th, 2021

DOl: https://doi.org/10.21203/rs.3.rs-266309/v1

License: (9) (1) This work is licensed under a Creative Commons Attribution 4.0 International License.

Read Full License

Version of Record: A version of this preprint was published at Soft Computing on November 12th, 2021. See the published version at https://doi.org/10.1007/s00500-021-06516-4. 


\title{
A bee colony optimization (BCO) and type-2 fuzzy approach to measuring the impact of speed perception on motor vehicle crash involvement
}

Marjana Čubranić-Dobrodolac, University of Belgrade, Faculty of Transport and Traffic Engineering Vojvode Stepe 305, 11000 Belgrade, Serbia

Libor Švadlenka, University of Pardubice - Faculty of Transport Engineering

Studentská 95, 53210 Pardubice, Czech Republic

Svetlana Čičević,

University of Belgrade, Faculty of Transport and Traffic Engineering Vojvode Stepe 305, 11000 Belgrade, Serbia

Aleksandar Trifunović, University of Belgrade, Faculty of Transport and Traffic Engineering Vojvode Stepe 305, 11000 Belgrade, Serbia

Corresponding author:

Momčilo Dobrodolac, University of Belgrade, Faculty of Transport and Traffic Engineering Vojvode Stepe 305, 11000 Belgrade, Serbia

E-mail: m.dobrodolac@sf.bg.ac.rs

\begin{abstract}
:
This paper examines how a driver's perception of various speed levels, as well as driver's speed perception from different positions, affect the propensity for motor vehicle crashes (MVCs). Data collection is performed in twelve experiments. 178 young drivers assessed the speed level from four positions; three of them relate to the speed perception of other vehicles on the road, while the remaining one represents the assessment of own speed. At each position, three speed levels were assessed: 30,50 , and $70 \mathrm{~km} / \mathrm{h}$. To process data, seven Type-2 fuzzy inference systems (T2FISs) are designed and tested in a sense of compliance with the empirical data. As a result, a relationship between the various forms of speed perception and participation in MVCs can be quantified. To examine the initial conclusions, the optimization of each of these T2FISs is performed by implementing the bee colony optimization $(\mathrm{BCO})$ metaheuristic. The $\mathrm{BCO}$ based algorithm proposed in this paper achieved an average improvement of $21.17 \%$ in the performance of the initial T2FIS structures. The final results indicate that the drivers whose speed perception of the vehicle they are looking at from the rear side, as well as of the own vehicle, is poor have an elevated risk toward participation in MVCs compared to other forms of speed perception. The best-found T2FIS structures can be used as a decision-making tool that quantifies the driver propensity for MVCs, which can be useful in various educational and recruitment procedures in the field of transportation and traffic safety.
\end{abstract}

Keywords: road safety; motor vehicle crashes; speed perception; fuzzy inference system; bee colony optimization; metaheuristic optimization

\section{Introduction}

Motor vehicle crashes (MVCs) result in 1.35 million deaths each year, which is around 3,700 deaths per day globally (WHO, 2018). Further, approximately 30 to 50 million people are either injured or permanently disabled every year. Moreover, MVCs cause great financial havoc of $\$ 518$ billion every 
year and thus costing countries from 1\% to 2\% of their GDP (Ashraf et al., 2019; Lotfi et al., 2019). However, more than $85 \%$ of crashes' fatalities and injuries occurred in developing countries (AlRukaibi et al., 2020). As in other parts of the world, road safety remains a major societal issue within the European Union (Murphy \& Morris, 2020). This is justified having in mind that more than 25,000 people died on the roads in Europe in 2018 (ETSC, 2020).

The fact that MVCs are the leading cause of death for the 15-29 age group (Bassani et al., 2020) motivated us to deeply investigate one possible factor that affects the involvement of young drivers in crashes. It is about the speed perception of young drivers considering their own and other vehicles on the road.

To improve road safety, insight is needed into preventable causes of MVCs. The causes of motor vehicle collisions are complex but broadly depend on the characteristics of drivers (Rolison et al., 2018). Skill level (McGwin \& Brown, 1999), inexperience (McCartt et al., 2003), risk-taking behaviors (Rolison et al., 2014) and excessive speed (Costa et al., 2020; Gonzales et al., 2005; Lam, 2003) have been implicated in the collisions of young drivers compared to drivers in other age ranges (Rolison et al., 2018). Young drivers often tend to risky behavior and also misjudges the speed of the vehicle, which makes them the drivers who are prone to participating in MVCs. In the literature, it is well-known that driving speed is one of the most significant factors in road safety.

In-depth MVC analysis provides a comprehensive view of all the factors involved in a crash (Aarts \& Van Schagen, 2006). Along with geometric characteristics, road surface conditions, traffic status, and driver behavior (Schlögl, 2020), speeding is among the most important variables influencing the occurrence of road crashes. Speed is a key risk factor in MVCs, increasing both the likelihood of a crash and the severity of resulting injuries (PAHO, 2018). Speed can be deceiving since many circumstances affect how it is perceived as a risk factor, including the type of vehicle, time of day, weather conditions, and the design and state of the road, etc. (PAHO, 2018). Driving speed, for example, is one of the behaviors affected by the driver's perception of the road's safety, and it is not necessarily compatible with the road's design speed (Misaghi and Hassan, 2005). If the speed chosen is not appropriate in a given situation, it may result in losing control and run-off-road crashes (Ben-Bassat \& Shinar, 2011; Janssen et al., 2006). Speed estimation of the own vehicle and other vehicles on the road is an important task for drivers and is also crucial to roadway safety. The results of the study conducted by Fildes and Lee (1989) show that the interaction of driving experience, road type, and drivers' gender affects speed estimation. Perceiving the speed of own vehicle and other vehicles is critical to ensure safe driving and, in particular, that the maneuvering actions do not violate the law, such as not going over the speed limit unintentionally and promptly maneuvering vehicles to avoid accident crashes (Wu et al., 2017). Close links exist between real vehicle speed and perceived vehicle speed, namely, based on the research by Zheng et al., 2018, the average driver's perceived speed is approximately twice less than the actual vehicle speed. Inaccurately estimated vehicle speed is the leading contributing factor to MVCs in highway tunnels (Zheng et al., 2018).

There is a question of what can be done to improve traffic safety, to save people's lives, and to reduce financial losses. A sanctioning system operates to respond to drivers who perform risky and illegal driving behaviors (McDonald et al., 2020); however, how to support the drivers whose perception of vehicle speed is poor? To what extent the drivers who inaccurately estimate vehicle speed are prone to be involved in MVCs and how to act preventively on them? The goal of this paper is exactly to answer these questions. By conducting 12 types of experiments related to vehicle speed perception and relating the results to the participants' driving history, we determine the driver's propensity for MVCs.

To model the driver characteristics, we propose the implementation of fuzzy logic; more concrete an interval Type-2 Fuzzy Inference System (T2FIS). Since speed perception, which is the main topic of this research, involves measurement imprecision and subjectivity, fuzzy logic is a particularly convenient method to apply. Furthermore, there is evidence about the very promising performance of this method compared to the traditional statistic methods (Čubranić-Dobrodolac et al., 2020a). Fuzzy logic is widely used as a tool for MVCs prediction. Some of the examples are the 
papers by Chai et al. (2017), Čubranić-Dobrodolac et al. (2019, 2020a, 2020b, 2020c), Dimitriou and Vlahogianni (2015), Nemet et al. (2019), Thakur (2014), Xiong et al. (2019). To test the stability of the initially obtained conclusions, we performed the optimization of T2FIS in the sense of maximizing the compliance with the empirical data, by using the Bee Colony Optimization (BCO) metaheuristic. According to the authors' knowledge, there is no example that the BCO metaheuristic is used in the field of traffic safety to improve the performance of the fuzzy inference system. Furthermore, the $\mathrm{BCO}$ based algorithm proposed in this paper is new and original, which can be considered as one of the main contributions of this paper.

\section{Literature review}

This section provides an insight into the previous papers published in the field of interest for this research. It is divided into two subsections. The first is related to the human factor in traffic safety and perception issues, while the second considers the fuzzy inference systems and corresponding optimization procedures.

\subsection{Perception and the human factor in traffic safety}

MVCs have been the result of the driving system (human, vehicle, road, environment) malfunctions which can be found in its components. Most of the safety studies conclude that human factors are the main cause of MVCs (Bucsuházy et al., 2020; Dingus et al., 2016; Weber et al., 2018). One of the crucial components concerning human factors is perception. Human perception is a complex phenomenon that affects the cognitive processes of driving. For this reason, it is one of the most important aspects to be considered in road safety research (Trifunović et al., 2019). The perception of the speed of movement is a basic visual function (Wu et al., 2017). Vision science studies show that optic flow is one of the main visual cues used for speed perception (Colombet et al., 2011; Lappe \& Grigo, 1999; Wu et al., 2017), but can be used to estimate the (un)safe distance between vehicles depending on the speed. Speed estimation by drivers is affected by a variety of sensory inputs, including visual, auditory, and, less significantly, kinesthetic and vestibular inputs. However, drivers primarily estimate their speed by analyzing visual input through a process called optic flow. As one moves through the environment, the visual field in front expands and passes by (Rudin-Brown, 2004). However, the low or high luminance and monotonous road environment make them a weak visual reference system. This weakness leads to the deficiency of the visual reference system for drivers and thus reduces their perception of their actual driving speed, resulting in an extremely high risk of over speeding and rear-end crashes (Zheng et al., 2018).

The studies that examine driver perception were conducted using different methodologies, by the experiments conducted in driving simulators (Ben-Bassat \& Shinar, 2011; Martens \& Brouwer, 2013; Pešić et al., 2019; Rudin-Brown, 2004; Wu et al., 2017; Zheng et al. 2018), real traffic situations (Troscianko et al., 1999), tablet PCs and smart boards (Cicevic et al., 2017), by driver self-reports, i.e. questionnaire (Ojsteršek \& Topolšek, 2019), and also in virtual reality (Trifunović et al., 2019). The sample ranges from 14 to 200 respondents, while statistical analysis was most often used for data processing. Since the beginning of this century, the speed-MVCs relationship was examined in many studies throughout the world, where a basic understanding of the issue can be summarized in the following statements: higher speeds are associated with a higher probability of being involved in an MVC; higher speeds are directly related to higher MVC severity; higher speed variation increases the risk of MVC (Gitelman et al., 2017). Table 1 summarizes the most important characteristics of the mentioned papers, such as the considered problem, research methodology, sample, processing data, and the key research results. 
Table 1. Key characteristics and research results related to driver perception and speed

\begin{tabular}{|c|c|c|c|c|}
\hline $\begin{array}{c}\text { Authors } \\
\text { (Publication year) }\end{array}$ & Problem Considered & $\begin{array}{c}\text { Research } \\
\text { methodology } \\
\text { (sample) }\end{array}$ & $\begin{array}{c}\text { Processing } \\
\text { data }\end{array}$ & Key research results \\
\hline $\begin{array}{l}\text { Troscianko, Wright } \\
\text { \& Wright (1999) } \\
\text { Rudin-Brown } \\
(2004)\end{array}$ & $\begin{array}{l}\text { Respondents estimated vehicle } \\
\text { speed in real traffic situations. } \\
\text { To assess the speed in a simulated } \\
\text { vehicle while viewing the road } \\
\text { from low and high eye height. }\end{array}$ & $\begin{array}{l}\text { Real traffic } \\
\text { situations }(10) \\
\text { Driving } \\
\text { simulation } \\
\text { (20 drivers) }\end{array}$ & $\begin{array}{l}\text { Statistical } \\
\text { analysis } \\
\text { Statistical } \\
\text { analysis }\end{array}$ & $\begin{array}{l}\text { Participants significantly } \\
\text { underestimated vehicle speed. } \\
\text { Drivers seated at a high eye } \\
\text { height drove faster than when } \\
\text { seated at low eye height. }\end{array}$ \\
\hline $\begin{array}{l}\text { Ben-Bassat \& Shinar } \\
\text { (2011) }\end{array}$ & $\begin{array}{l}\text { To test the combined effects of } \\
\text { roadway shoulder width, } \\
\text { guardrail existence, and roadway } \\
\text { geometry on perceived safe } \\
\text { driving speed and estimated road } \\
\text { safety. }\end{array}$ & $\begin{array}{l}\text { Driving } \\
\text { simulation } \\
\text { ( } 22 \text { drivers })\end{array}$ & $\begin{array}{l}\text { Statistical } \\
\text { analysis }\end{array}$ & $\begin{array}{l}\text { Roadway geometry can be used } \\
\text { to reduce driving speeds, but at } \\
\text { the same time, it can have a } \\
\text { negative effect on maintaining a } \\
\text { stable lane position in sharp } \\
\text { curves. }\end{array}$ \\
\hline $\begin{array}{l}\text { Martens \& Brouwer } \\
\text { (2013) }\end{array}$ & $\begin{array}{l}\text { The influence of external } \\
\text { distractions and internal cognitive } \\
\text { processes on driving. }\end{array}$ & $\begin{array}{l}\text { Driving } \\
\text { simulator } \\
\text { (60 drivers) }\end{array}$ & $\begin{array}{l}\text { Statistical } \\
\text { analysis }\end{array}$ & $\begin{array}{l}\text { Both internal and external } \\
\text { distractions affected driving } \\
\text { speed. }\end{array}$ \\
\hline $\begin{array}{l}\text { Sun, Zhuang, Wu, } \\
\text { Zhao \& Zhang } \\
\text { (2015) }\end{array}$ & $\begin{array}{l}\text { The importance of pedestrians' } \\
\text { estimation of vehicle speed and } \\
\text { stopping distance when they are } \\
\text { crossing streets. }\end{array}$ & $\begin{array}{l}\text { Field } \\
\text { experiment } \\
(44)\end{array}$ & $\begin{array}{l}\text { Statistical } \\
\text { analysis }\end{array}$ & $\begin{array}{l}\text { When the speed of the oncoming } \\
\text { vehicle exceeded the upper bound } \\
\text { of the accurate interval, } \\
\text { pedestrians were more likely to } \\
\text { underestimate the vehicle speed, } \\
\text { increasing their risk of } \\
\text { incorrectly deciding to cross } \\
\text { when it is not safe to do so. }\end{array}$ \\
\hline $\begin{array}{l}\text { Cicevic, Trifunovic, } \\
\text { Mitrovic, \& Nesic } \\
\text { (2017) }\end{array}$ & $\begin{array}{l}\text { Usability analysis of different } \\
\text { presentation media design for } \\
\text { vehicle speed assessment }\end{array}$ & $\begin{array}{l}\text { Tablet PC and } \\
\text { Smartboard } \\
(14 \\
\text { respondents })\end{array}$ & $\begin{array}{l}\text { Statistical } \\
\text { analysis }\end{array}$ & $\begin{array}{l}\text { There are differences between the } \\
\text { medium on which tasks are } \\
\text { presented, but also that accuracy } \\
\text { of the assessment is influenced } \\
\text { by the different analyzed speeds } \\
\text { of vehicles, as well as the } \\
\text { perspective from which the } \\
\text { vehicle is observed. }\end{array}$ \\
\hline $\begin{array}{l}\text { Wu, Yu, Doherty, } \\
\text { Zhang, Kust \& Luo } \\
\text { (2017) }\end{array}$ & $\begin{array}{l}\text { To examine the effects of } \\
\text { multiple factors such as image } \\
\text { scale, speed, road type, driving } \\
\text { experience, and gender on the } \\
\text { speed perception of drivers' } \\
\text { vehicles. }\end{array}$ & $\begin{array}{l}\text { Driving } \\
\text { simulator - } \\
\text { Video clips } \\
(30)\end{array}$ & $\begin{array}{l}\text { Statistical } \\
\text { analysis }\end{array}$ & $\begin{array}{l}\text { The study shows the effect of } \\
\text { multidimensional influential } \\
\text { factors on perceived vehicle } \\
\text { speed from the drivers' } \\
\text { perspective. }\end{array}$ \\
\hline $\begin{array}{l}\text { Zheng, Du, Xiang, \& } \\
\text { Chen (2018) }\end{array}$ & $\begin{array}{l}\text { Influence of multiscale visual } \\
\text { information on the driver's } \\
\text { perceived speed in highway } \\
\text { tunnels. }\end{array}$ & $\begin{array}{l}\text { Driving } \\
\text { simulation } \\
(30 \text { drivers })\end{array}$ & $\begin{array}{l}\text { Statistical } \\
\text { analysis }\end{array}$ & $\begin{array}{l}\text { The speed overestimation of } \\
\text { drivers in the middle of tunnels } \\
\text { results from the presence of high- } \\
\text { frequency visual information, } \\
\text { while speed underestimation } \\
\text { results from the presence of } \\
\text { medium-frequency and low- } \\
\text { frequency visual information. }\end{array}$ \\
\hline $\begin{array}{l}\text { Ojsteršek \& } \\
\text { Topolšek (2019) }\end{array}$ & $\begin{array}{l}\text { The research focuses on selected } \\
\text { visual and cognitive distractions } \\
\text { that the driver is faced with, and } \\
\text { on their influence on detecting } \\
\text { and perceiving changes in the } \\
\text { traffic environment. }\end{array}$ & $\begin{array}{l}\text { Driver self- } \\
\text { report } \\
\text { (213 drivers) }\end{array}$ & $\begin{array}{l}\text { Exploratory } \\
\text { factor analysis, } \\
\text { Confirmatory } \\
\text { factor analysis, } \\
\text { and Structural } \\
\text { Equation } \\
\text { Modelling }\end{array}$ & $\begin{array}{l}\text { Drivers that visually focus on } \\
\text { traffic signals and pedestrians } \\
\text { and think about driving speed, } \\
\text { and driving rules, tend to notice } \\
\text { crucial changes in the traffic } \\
\text { environment more often. }\end{array}$ \\
\hline $\begin{array}{l}\text { Pešić, Trifunović, } \\
\text { Ivković, Čičević \& } \\
\text { Žunjić (2019) }\end{array}$ & $\begin{array}{l}\text { The paper whether there are } \\
\text { differences in driver's estimation } \\
\text { of passenger car speed when } \\
\text { daytime running lights (DRL) are } \\
\text { turned on or off. }\end{array}$ & $\begin{array}{l}\text { Driving } \\
\text { simulator } \\
\text { (185 drivers) }\end{array}$ & $\begin{array}{l}\text { Statistical } \\
\text { analysis }\end{array}$ & $\begin{array}{l}\text { The results indicate that there are } \\
\text { differences in the estimation of } \\
\text { passenger car speed when DRL } \\
\text { are turned on or off. }\end{array}$ \\
\hline $\begin{array}{l}\text { Trifunović, Čičević, } \\
\text { Lazarević, Dragović, } \\
\text { Vidović, Mošić \& } \\
\text { Otat (2019) }\end{array}$ & $\begin{array}{l}\text { To appraise the relationship } \\
\text { between Perception of 3D virtual } \\
\text { road markings and the estimation } \\
\text { of vehicle speed. }\end{array}$ & $\begin{array}{l}\text { Virtual reality } \\
\text { (63 drivers) }\end{array}$ & $\begin{array}{l}\text { Statistical } \\
\text { analysis }\end{array}$ & $\begin{array}{l}\text { There are statistically significant } \\
\text { differences between drivers' } \\
\text { willingness to reduce vehicle } \\
\text { speed as a response to the two } \\
\text { types of 3D road markings. }\end{array}$ \\
\hline $\begin{array}{l}\text { Our study } \\
\text { (2020) }\end{array}$ & $\begin{array}{l}\text { How speed perception of vehicles } \\
\text { influences the occurrence of } \\
\text { crashes. }\end{array}$ & $\begin{array}{l}\text { Driving } \\
\text { simulator }(178 \\
\text { young drivers })\end{array}$ & $\begin{array}{l}\text { T2FIS and } \\
\text { BCO } \\
\text { metaheuristic }\end{array}$ & $\begin{array}{l}\text { The drivers whose speed } \\
\text { perception of own vehicle and } \\
\text { vehicle in front is poor, are more } \\
\text { prone to MVCs }\end{array}$ \\
\hline
\end{tabular}


Based on the literature review, previous studies were mainly limited to the investigation of the interactions among different factors that affect speed perception of drivers' vehicles. There is a need to explore more how the speed perception of vehicles influences the occurrence of MVCs.

\subsection{The optimization of fuzzy inference systems}

The optimization of the Fuzzy Inference System (FIS) represents a tuning of the characteristics of FIS to minimize or maximize the objective function, depending on the type of the considered task. Here it is mostly the minimization task because the performance of FIS is generally measured as the level of deviation from certain empirical data. There are numerous examples where this procedure is useful. In the case of the current research, we implement the optimization of FIS intending to perform a stability analysis of the initial solution in the sense of the relationships between different FISs.

Many papers deal with FIS optimization issues. Therefore, here we will offer just a review of the most frequently used techniques in the field in the last two years, from 2019 to 2020, which is shown in Table 2. An interesting fact to notice here is that general principles of FIS optimization set up in the past are valid also nowadays and the changes are in terms of newly applied optimizations methods, which have been proposed in the meanwhile. Guillaume (2001) systemized the procedures for fuzzy rule generations from empirical data and structured the optimization methods as "shared partitions", "clustering", and "hybrid methods". The hybrid methods were based on the implementation of neuro-fuzzy modeling or heuristic algorithms, mentioning Genetic Algorithms (GA) as the most popular at that time.

One direction in the optimization procedures is related to the implementation of an adaptive neuro-fuzzy inference system - ANFIS (Jang, 1993). Certain authors combine the ANFIS method with other metaheuristics. Nath et al. (2020) combined particle swarm optimization (PSO) with ANFIS to optimize the rainfall-runoff relationship. Chouksey et al. (2020) applied an improved artificial neural network-based particle swarm optimization (IANN-PSO) method to maximize the power from the solar power system.

A development of metaheuristic approaches based on mimicking the behavioral patterns observed in nature has been very popular in recent decades. These techniques were successfully implemented in many cases for solving complex computational tasks, such as optimization of FIS.

As previously mentioned, genetic algorithms (GA) are frequently used. Nagammai et al. (2020) used GA to tune the membership functions of FIS for water level control in a conical tank process. Some authors further improved GA algorithms. For example, Chu et al. (2020) applied a nondominated sorting genetic algorithm-II (NSGA-II), as a multiobjective optimization method derived from GA, to optimize a fuzzy proportional-integral-derivative (PID) controller for automatic train operation. El-Gendy et al. (2020) proposed a hybrid of GA and PSO to tune the parameters of different adaptive PID controllers.

Mahmoodabadi \& Nejadkourki (2020) applied FIS to regulate the control parameters of the PID controller for a quarter-car model, where the PSO algorithm is proposed to ascertain the optimum gains of the designed controller. The idea of PSO is inspired by the social behavior of bird flocking or fish schooling. The PSO metaheuristic is applied also by Zorić et al. (2019) for a self-tuning fuzzy logic controller of the piezo-fiber reinforced composite actuator.

Ajithapriyadarsini et al. (2019) used differential evolution (DE) to optimize the gain of a fuzzy logic-DE algorithm-based PID controller. Ab Talib et al. (2019) proposed an advanced firefly algorithm (AFA) for improving vehicle dynamics. Azizi et al. (2019) used Multi-Verse Optimizer (MVO) for the optimization of a fuzzy controller applied to a seismically excited nonlinear building. Tremante et al. (2019) applied the Direct Search (DS) method, specifically the pattern search, for tuning of the membership functions of a FIS.

The Ant Colony Optimization (ACO) algorithm is applied by Aldair et al. (2019) to tune and find the best parameters of the output membership function of the fuzzy controller for robot moves. Precup et al. (2020) implemented a relatively new metaheuristic called Grey Wolf Optimizer (GWO) 
inspired by specific leadership styles of grey wolves. Abd Ali et al. (2020) presented a quantuminspired lightning search algorithm (QLSA) to optimize the performance of the induction motor under different speed and load conditions. Karar, El-Garawany, \& El-Brawany, (2020) applied the Invasive Weed Optimization (IWO) algorithm inspired by the behavior of weed colonies. Elias \& Mat Yahya (2020) applied the bats sonar algorithm (BSA) which is inspired by the echolocation process of a colony of bats to find food or prey.

Mohammadzadeh \& Kayacan (2020) proposed the particle swarm optimization and artificial bee colony algorithm (PSO-ABC). The algorithms based on the bees demonstrated very competitive results in optimization procedures. For example, Yazid et al. (2019) demonstrated that the ABC outperforms the GA and PSO approach in optimizing the fuzzy logic controller for trajectory tracking of a quadcopter drone. In our study, we combine "shared partition" and "hybrid method" as segmented by Guillaume (2001). One class of shred partition is "One rule per pair" and the principle proposed by Wand and Mendel - WM (1992) is the most popular here. Therefore, we combine the WM approach with a metaheuristic algorithm based on Bee Colony Optimization (BCO) to perform the optimization of different FISs.

Table 2. Recently used methods for FIS optimization

\begin{tabular}{|c|c|c|c|}
\hline Authors & Considered problem & $\begin{array}{c}\text { Method of } \\
\text { optimization }\end{array}$ & Type of FIS \\
\hline $\begin{array}{l}\text { Ab Talib, Mat Darus \& Mohd Samin } \\
\text { (2019) }\end{array}$ & Improving vehicle dynamics & AFA & Type-1 \\
\hline $\begin{array}{l}\text { Ajithapriyadarsini, Mary \& } \\
\text { Iruthayarajan (2019) }\end{array}$ & PID controller in power system & $\mathrm{DE}$ & Type-1 \\
\hline $\begin{array}{l}\text { Aldair, Rashid, Rashid, \& Alsaedee } \\
\text { (2019) }\end{array}$ & Robot moves modeling & $\mathrm{ACO}$ & Type-1 \\
\hline $\begin{array}{l}\text { Azizi, Ghasemi, Ejlali \& Talatahari } \\
\text { (2019) }\end{array}$ & $\begin{array}{l}\text { Behavior modeling of the } \\
\text { building structure }\end{array}$ & MVO & Type-1 \\
\hline Tremante, Yen \& Brea (2019) & Water tank system control & DS & Type-1 \\
\hline Yazid, Garratt \& Santoso (2019) & $\begin{array}{l}\text { Trajectory tracking of a } \\
\text { quadcopter drone }\end{array}$ & $\mathrm{ABC}, \mathrm{GA}, \mathrm{PSO}$ & Type-1 \\
\hline $\begin{array}{l}\text { Zorić, Tomović, Obradović, Radulović } \\
\text { \& Petrović (2019) }\end{array}$ & $\begin{array}{l}\text { Controller of the piezo-fiber } \\
\text { reinforced composite actuator }\end{array}$ & PSO & Type-1 \\
\hline $\begin{array}{l}\text { Abd Ali, Hannan, Mohamed, Jern \& } \\
\text { Abdolrasol (2020) }\end{array}$ & $\begin{array}{l}\text { Improving the performance of } \\
\text { induction motor }\end{array}$ & QLSA & Type-1 \\
\hline Chouksey, Awasthi, \& Singh (2020) & Solar power system modeling & IANN-PSO & Type-1 \\
\hline Chu, Yu, Dong, Lin \& Yuan (2020) & $\begin{array}{l}\text { Control of automatic train } \\
\text { operation }\end{array}$ & NSGA-II & Type-1 \\
\hline $\begin{array}{l}\text { El-Gendy, Saafan, Elksas, Saraya, \& } \\
\text { Areed (2020) }\end{array}$ & $\begin{array}{l}\text { PID controller in the chemical } \\
\text { process }\end{array}$ & GA-PSO & Type-1 \\
\hline Elias \& Mat Yahya (2020) & $\begin{array}{l}\text { Controller of a DC motor for the } \\
\text { crane system }\end{array}$ & BSA & Type-1 \\
\hline $\begin{array}{l}\text { Karar, El-Garawany \& El-Brawany } \\
\text { (2020) }\end{array}$ & $\begin{array}{l}\text { Regulating anti-cancer drug } \\
\text { delivery }\end{array}$ & IWO & Intuitionistic \\
\hline Mohammadzadeh \& Kayacan (2020) & $\begin{array}{l}\text { Frequency regulation in ac } \\
\text { microgrid }\end{array}$ & PSO-ABC & Type-2 \\
\hline Mahmoodabadi \& Nejadkourki (2020) & $\begin{array}{l}\text { PID controller for a quarter-car } \\
\text { model }\end{array}$ & PSO & Type-1 \\
\hline $\begin{array}{l}\text { Nagammai, Latha \& Varatharajan } \\
\text { (2020) }\end{array}$ & $\begin{array}{l}\text { Water level control in a conical } \\
\text { tank process }\end{array}$ & GA & Type-1 \\
\hline Nath, Mthethwa \& Saha (2020) & Rainfall-Runoff modeling & ANFIS-PSO & Type-1 \\
\hline $\begin{array}{l}\text { Precup, Voisan, Petriu, Tomescu, } \\
\text { David, Szedlak-Stinean, \& Roman } \\
\text { (2020) }\end{array}$ & The trajectory of the robots & GWO & Type-1 \\
\hline Our study & Driver behavior modeling & $W M-B C O$ & Type-2 \\
\hline
\end{tabular}

\section{Research methodology}

The research methodology is structured into three parts. The first relates to the explanation of performed experiments and the procedure of data collection. Section 3.2 is about forming different T2FIS structures. Finally, the last subsection explains the procedure of T2FIS optimization using the 
BCO metaheuristic. The concept of research is illustrated in Fig. 1 and a more detailed explanation is offered in the following text.

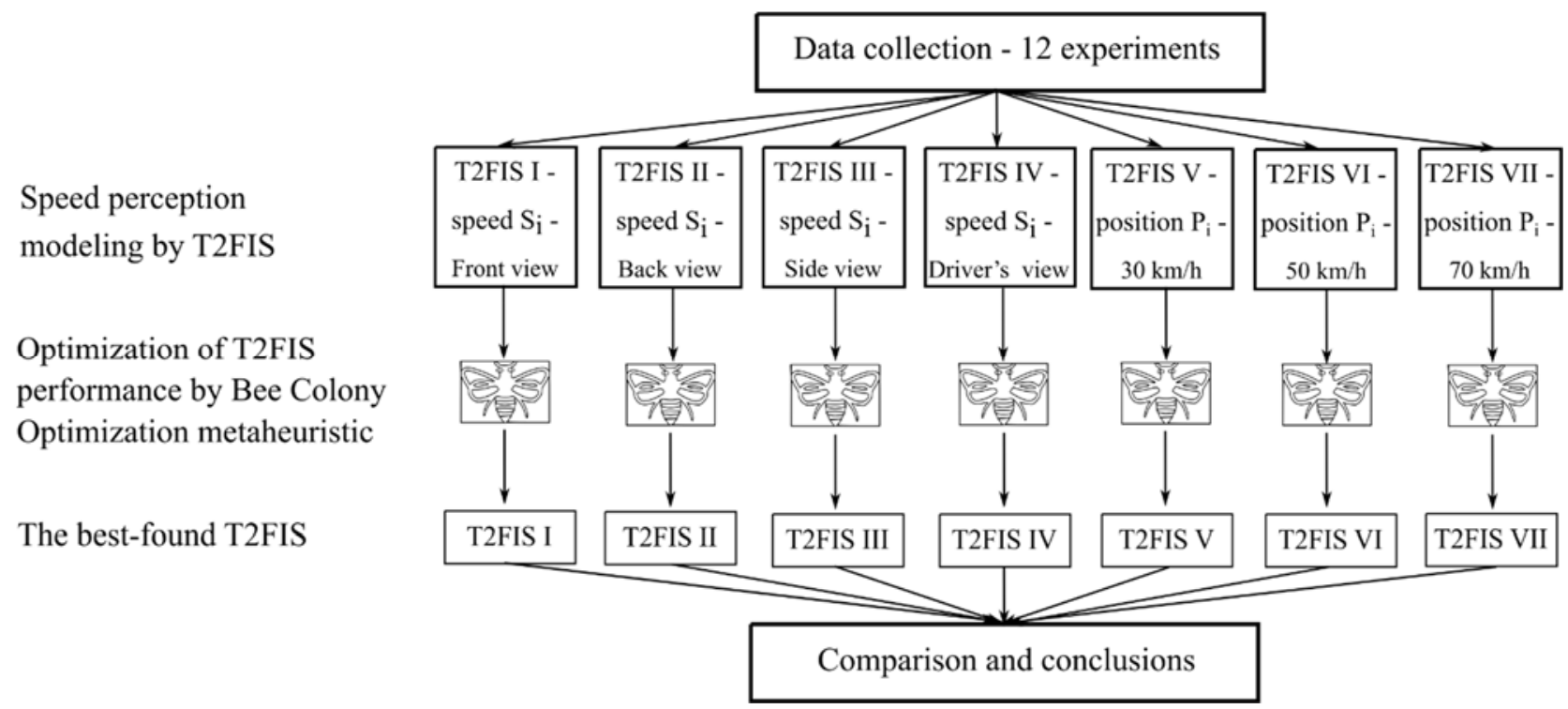

Figure 1. A configuration of the research: the parameter $S_{i}(i=1,3)$ takes the following values: $S_{1}=30 \mathrm{~km} / \mathrm{h}, S_{2}=50 \mathrm{~km} / \mathrm{h}$, and $S_{3}=70 \mathrm{~km} / \mathrm{h}$; the parameter $P_{j}(j=1,4)$ takes the following values: $P_{l}=$ Front view, $P_{2}=$ Rear view, $P_{3}=$ Side view, and $P_{4}=$ Driver's seat perspective

\subsection{Experiment and data collection}

\section{Driving simulator}

Driving simulator experiments have been widely applied in driving behavior studies as well as speed perception studies (Zheng et al., 2018; Pešić et al., 2019). For this study, the experiments took place in a PC-based driving simulator. The driving simulator incorporates three 4200 plasma displays that give the responders a $180^{\circ}$ horizontal and $50^{\circ}$ vertical field of view of the simulated environment. Each display has a resolution of 1360 x 768 pixels and a refresh rate of $60 \mathrm{~Hz}$ (Bıçaksız et al., 2019; Pešić et al., 2019). This driving simulator can be applied to study issues related to road traffic safety under controlled experimental conditions.

Many studies have classified driving simulators (Hussain et al., 2020; Hussain et al., 2019; Saluäär, 2000; Wynne et al., 2019). Saluäär (2000) in his study classified driving simulators as low, mid-level, or high-level. The low-level simulators are ordinary personal computers equipped with a steering wheel and pedals. High-level simulators usually have huge motion base systems. Simulators between these two categories are called mid-level (Saluäär, 2000; Mathur, 2010). The simulator used in this study consists of three LCD monitors, three connected computers, and a cockpit for the driver that transposes the vibration from the virtual environment on the driver. According to the above classification, this simulator can be classified as a mid-level one.

Driving simulators have two levels of validity: 1 . Physical and 2. Behavioral. Physical validity measures the degree to which the simulator dynamics and visual system reproduce the vehicle being simulated. The behavioral validity of a driving simulator, according to Blana (1997), is defined as the comparison of driving performance indices from a particular experiment on a real road with indices from an experiment in a driving simulator which is as close as it can be to the real environment. On the other hand, Blaauw (1982) in his study proposed two types of driving behavioral validity: 1. Absolute and 2. Relative. A driving simulator is absolutely valid if the difference between the magnitudes of critical driver performance variables to example speed, acceleration, etc., observed in the driving simulator and those in the real world is statistically insignificant (Mathur, 2010). A driving simulator is relatively valid if the differences with experimental conditions are in the same direction, and have a similar magnitude (Yan et al., 2008; Mathur, 2010). 
The simulator used in the experiment was developed and funded by a team of experts from the Faculty of Transport and Traffic Engineering - University of Belgrade. Before each experiment, the simulator is set up to mimic reality as well as possible. Taking into account all the above, as well as the fact that the simulator used in this study is similar by its characteristics to other simulators used in the published research papers (Boot et al, 2015; Wynne et al., 2019; Pešić et al., 2019; Hussain et al., 2019; Bıçaksız et al, 2019; Kummetha et al., 2020; Hussain et al., 2020), the simulator used in this experiment can be considered as valid for this type of research and belongs to the mid-level group of simulators.

\section{Selection of vehicle for experiment and vehicle speed}

The vehicle used for the experiment was Peugeot 307, the hatchback version with five doors. Vehicle dimensions are: length $4210 \mathrm{~mm}$, width $1730 \mathrm{~mm}$, and height of $1510 \mathrm{~mm}$. The color of the vehicle is the factory golden yellow (color code: kaw Jaune Persepolis met). The facts from the literature suggest that it is easier to spot the vehicle if there is a higher contrast between the vehicle color and the environment. In general, brighter colored vehicles have a higher contrast with the environment, so it is, therefore, easier to perceive (Pešić et al., 2019; Allen \& Clark, 1964; Dahlstedt \& Rumar, 1973). Values of vehicle test speed are permanently determined due to legal restrictions: the limit of $30 \mathrm{~km} / \mathrm{h}$ in a school zone; limit of $50 \mathrm{~km} / \mathrm{h}$ in inhabited area and limit of $70 \mathrm{~km} / \mathrm{h}$ (OGRS, 2020; Pešić et al., 2019; Cicevic, et al., 2017). The length of the route traveled by the experimental passenger car was $300 \mathrm{~m}$.

\section{Experimental protocol}

This paper presents the experiment carried out in the Laboratory of Traffic Psychology, Faculty of Transport and Traffic Engineering in Belgrade (Cicevic, et al., 2017). For this testing, twelve driving situations, three speeds from four perspectives, are shown on a driving simulator to the participants. In the driving simulator, the vehicles are shown in different perspectives (with certain speed from "FRONT view" (F), as well as from "REAR view" (R), from the side of the vehicle "SIDE view" (S), and the angle of the "DRIVER'S SIDE PERSPECTIVE" (D) (see Fig. 2). The present study focused on the trajectory characteristics of free-flow driving with no roadside interference. The participants viewed the traffic scenarios in a two-lane undivided road, during the daytime on a sunny day. The driving environment included usual traffic signalization and vegetation, there were no additional objects added in the traffic scenes to avoid the impact on participants' expectations about the movement of the visual targets, and to prevent distraction. At the beginning of the experiment, each participant received his combination of experimental stimulus order, which was chosen by using a random number generator. This procedure was carried out to neutralize the anchoring effect, through counterbalancing. Counterbalancing is accomplished by randomizing the order of presentations of the test stimuli. Each respondent estimated speed for all twelve traffic situations. Speed estimation made by each participant was registered immediately after watching each traffic situation in the driving simulator. No pre-defined answers are given (Pešić et al., 2019). All participants had identical driving environment, identical test speeds, route length, and speed assessment time. At the end of each scenario, respondents gave their answers.

A detailed explanation of each question and requested data from the participants are offered before the start of the experiment. During the experiment, three analysts were present in the Laboratory giving instructions and support to the participants. Particular attention is given to reporting the participation in MVCs. A participant was considered as the one who participated in the MVC only if he/she had acted as a driver and if the MVC had occurred by his/her fault. MVCs that appeared at the parking places or those that can be considered as random events are not taken into consideration. To prove the participation in an MVC, we asked the participants about the detailed description of the MVC, including the court judgments, type and level of penalties, obtained penalty points, etc. A certified traffic safety expert carried out this examination. 


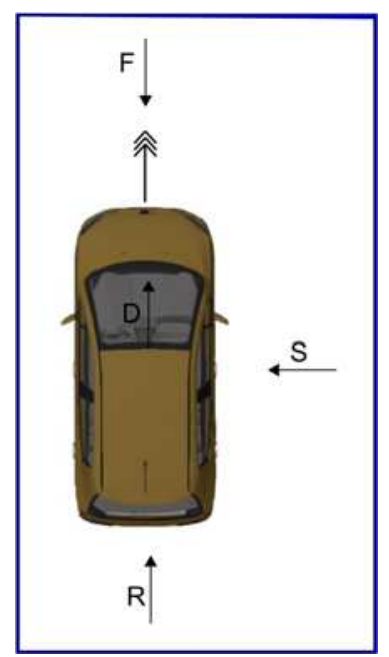

A)

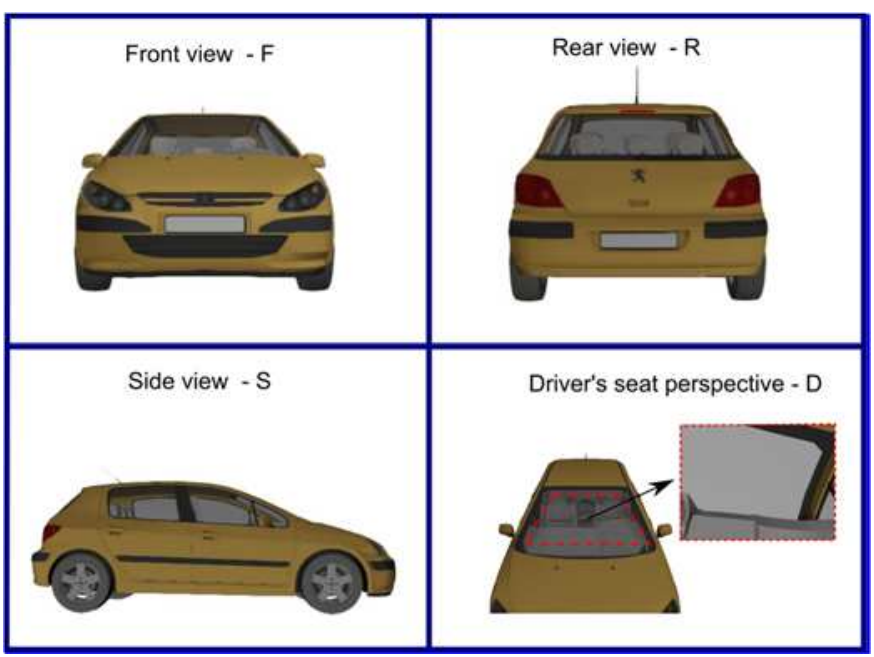

B)

Figure 2. Presentation of vehicle speed perception for four different perspectives A) four different perspectives B) appearance of the vehicle from the perspective of the respondents

\section{Sample}

The sample included 178 young drivers aged from 19 to 22 . A motive to research young drivers is the fact that MVCs represent a leading cause of deaths in this population (WHO, 2018; Jannusch et al., 2020; Wang et al., 2020). Besides the expected valuable conclusions from this research, we believe this kind of study can increase the awareness of young people about the significance of proper behavior in traffic, potentially saving someone's life. We implemented a convenience sampling technique (a non-probability technique). To collect data on young drivers, 241 students from the Faculty of Transport and Traffic Engineering - University of Belgrade were invited. From this number, 178 fulfilled the conditions of participation and accepted to take part in the experiment. The main conditions were possession of a driver's license and the absence of any previous experience with the driving simulator. These conditions were set to provide the same background for all participants. The response rate was very high, which can be explained by the previous educational connection between the authors and participants. The study adhered to the Code of Ethics and Conduct of the Serbian Psychological Association. Respondents did not receive any compensation for participation.

Because the implemented sampling technique does not include a random selection of participants, it would be welcome to expand the number of participants in future research, considering also other populations of young drivers. Besides, further research covering the drivers of all ages would be also welcome.

\subsection{The proposed model based on testing the T2FIS structures}

The essence of the model is the design and testing of type-2 FIS structures. There are seven categories of T2FIS structures that are tested in this research (Fig. 3). They can be classified into two groups. The first (Part a) in Fig. 3) considers the assessment of exact speed value (30, 50, or $70 \mathrm{~km} / \mathrm{h}$ ) from four positions. Therefore, there are three categories of T2FIS in this group. The second group (Part b) in Fig. 3) relates to testing the impact of different positions for speed perception on the occurrence of MVCs. These positions are: Front view, Rear view, Side view, and Driver's seat perspective. Accordingly, there are four categories of T2FIS in the second group. In both groups, as an output variable is taken the number of experienced MVCs. The result of testing the mentioned seven T2FIS structures should be a conclusion which of them describes the empirical data in the most accurate way. This finding should lead to the determination of the most significant predictor of MVCs occurrence. 


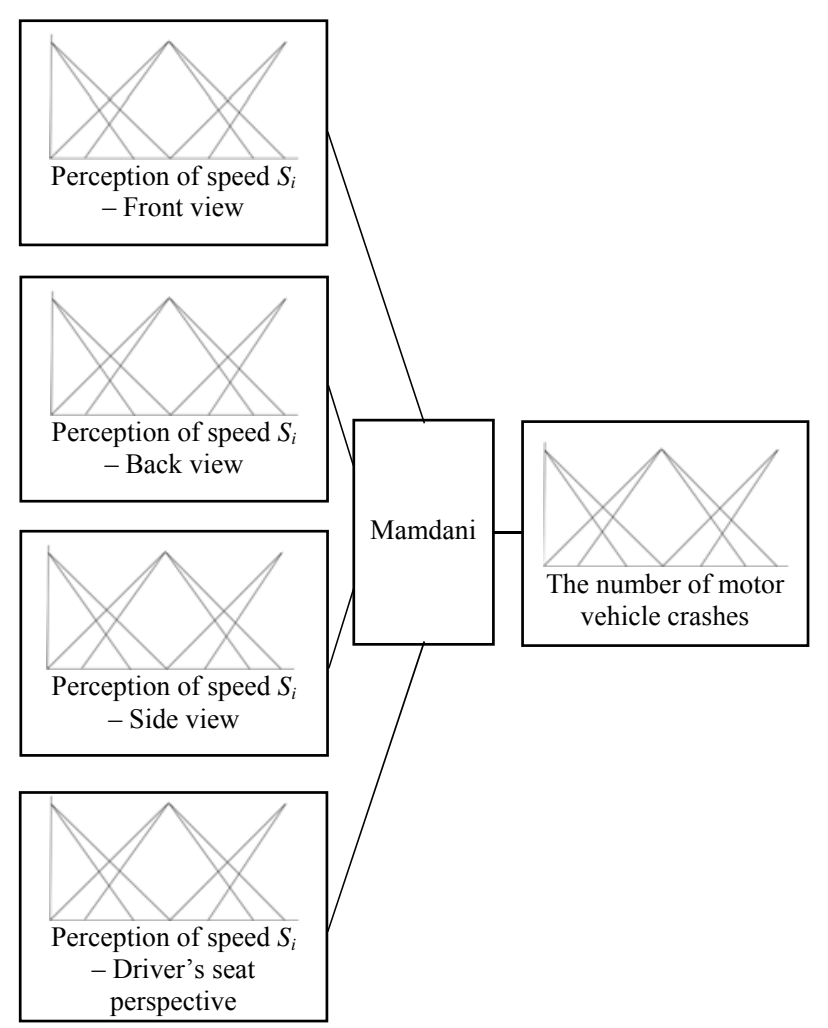

(a)

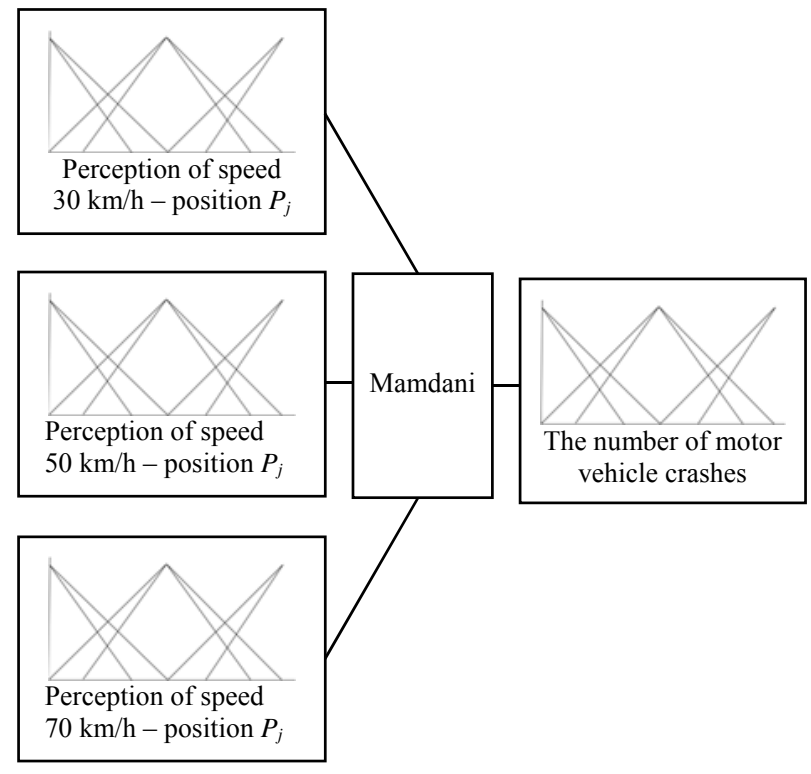

(b)

Figure 3. The proposed model of speed perception: (a) the parameter $S_{i}(i=1,3)$ takes the following values: $S_{I}=30 \mathrm{~km} / \mathrm{h}$, $S_{2}=50 \mathrm{~km} / \mathrm{h}$, and $S_{3}=70 \mathrm{~km} / \mathrm{h}$; (b) the parameter $P_{j}(j=1,4)$ takes the following values: $P_{l}=$ Front view, $P_{2}=$ Rear view, $P_{3}=$ Side view, and $P_{4}=$ Driver's seat perspective

To form the T2FIS, two main tasks are to design the membership functions and the fuzzy rule database. For both purposes, we use the empirical data collected in the experiments previously explained.

In total, there are twelve input variables and one output to be used in different ways in seven categories of T2FIS. The input variables are marked by $x_{i}$, where $i$ takes values from 1 to 12 , and the output variable is marked by $y$. A description of the used variables and the corresponding descriptive statistics of the sample are shown in Table 3, while the distribution of particular variables in each T2FIS category is presented in Table 4. It can be noticed that certain participants made very huge errors in their assessment. This may be explained by the young age of participants, having in mind that all of them had very limited experience in driving.

Table 3. Used variables - domain intervals and descriptive statistics of the sample

\begin{tabular}{|c|c|c|c|c|c|c|}
\hline \multirow[b]{2}{*}{ Variable } & \multirow[b]{2}{*}{$\begin{array}{l}\text { Position of speed } \\
\text { assessment }\end{array}$} & \multirow[b]{2}{*}{$\begin{array}{l}\text { Vehicle } \\
\text { speed }\end{array}$} & \multicolumn{4}{|c|}{ Descriptive statistics of the sample } \\
\hline & & & $\begin{array}{l}\text { Number of } \\
\text { respondents }\end{array}$ & $\begin{array}{c}\text { Minimum } \\
\text { assessment error }\end{array}$ & $\begin{array}{c}\text { Mean } \\
\text { assessment error }\end{array}$ & $\begin{array}{c}\text { Maximum } \\
\text { assessment error }\end{array}$ \\
\hline$x_{1}$ & Front view & $30 \mathrm{~km} / \mathrm{h}$ & 178 & -20 & 14.31 & 50 \\
\hline$x_{2}$ & Front view & $50 \mathrm{~km} / \mathrm{h}$ & 178 & -40 & 2.16 & 70 \\
\hline$x_{3}$ & Front view & $70 \mathrm{~km} / \mathrm{h}$ & 178 & -65 & -39.52 & 20 \\
\hline$x_{4}$ & Rear view & $30 \mathrm{~km} / \mathrm{h}$ & 178 & -5 & 23.79 & 90 \\
\hline$x_{5}$ & Rear view & $50 \mathrm{~km} / \mathrm{h}$ & 178 & -20 & 16.08 & 70 \\
\hline$x_{6}$ & Rear view & $70 \mathrm{~km} / \mathrm{h}$ & 178 & -50 & -23.12 & 50 \\
\hline$x_{7}$ & Side view & $30 \mathrm{~km} / \mathrm{h}$ & 178 & -10 & 26.63 & 100 \\
\hline$x_{8}$ & Side view & $50 \mathrm{~km} / \mathrm{h}$ & 178 & -20 & 20.68 & 90 \\
\hline$x_{9}$ & Side view & $70 \mathrm{~km} / \mathrm{h}$ & 178 & -54 & -23.02 & 40 \\
\hline$x_{10}$ & Driver's perspective & $30 \mathrm{~km} / \mathrm{h}$ & 178 & -10 & 22.27 & 100 \\
\hline$x_{11}$ & Driver's perspective & $50 \mathrm{~km} / \mathrm{h}$ & 178 & -20 & 15.34 & 100 \\
\hline$x_{12}$ & Driver's perspective & $70 \mathrm{~km} / \mathrm{h}$ & 178 & -65 & -43.67 & 0 \\
\hline$y$ & & & 178 & 0 & 0.18 & 3 \\
\hline
\end{tabular}


Table 4. Categories of tested fuzzy interference systems

\begin{tabular}{ccl}
\hline $\begin{array}{c}\text { FIS category } \\
\text { No. }\end{array}$ & $\begin{array}{c}\text { Name of T2FIS } \\
\text { category }\end{array}$ & \multicolumn{1}{c}{ Used variables } \\
\hline I & T2FIS_30 & $x_{1}, x_{4}, x_{7}, x_{10}, y$ \\
II & T2FIS_50 & $x_{2}, x_{5}, x_{8}, x_{11}, y$ \\
III & T2FIS_70 & $x_{3}, x_{6}, x_{9}, x_{12}, y$ \\
IV & T2FIS_F & $x_{1}, x_{2}, x_{3}, y$ \\
V & T2FIS_R & $x_{4}, x_{5}, x_{6}, y$ \\
VI & T2FIS_S & $x_{7}, x_{8}, x_{9}, y$ \\
VII & T2FIS_D & $x_{10}, x_{11}, x_{12}, y$ \\
\hline
\end{tabular}

The descriptive statistics of the sample is a starting point for the membership functions design. Since the domain of input variables contain both positive and negative values, which represents some sort of a specific situation, we propose an adequate algorithm (Table 5) to define the points with the highest degree of membership $(\mu(x)=1)$.

Table 5. Pseudocode of the algorithm for membership functions generation

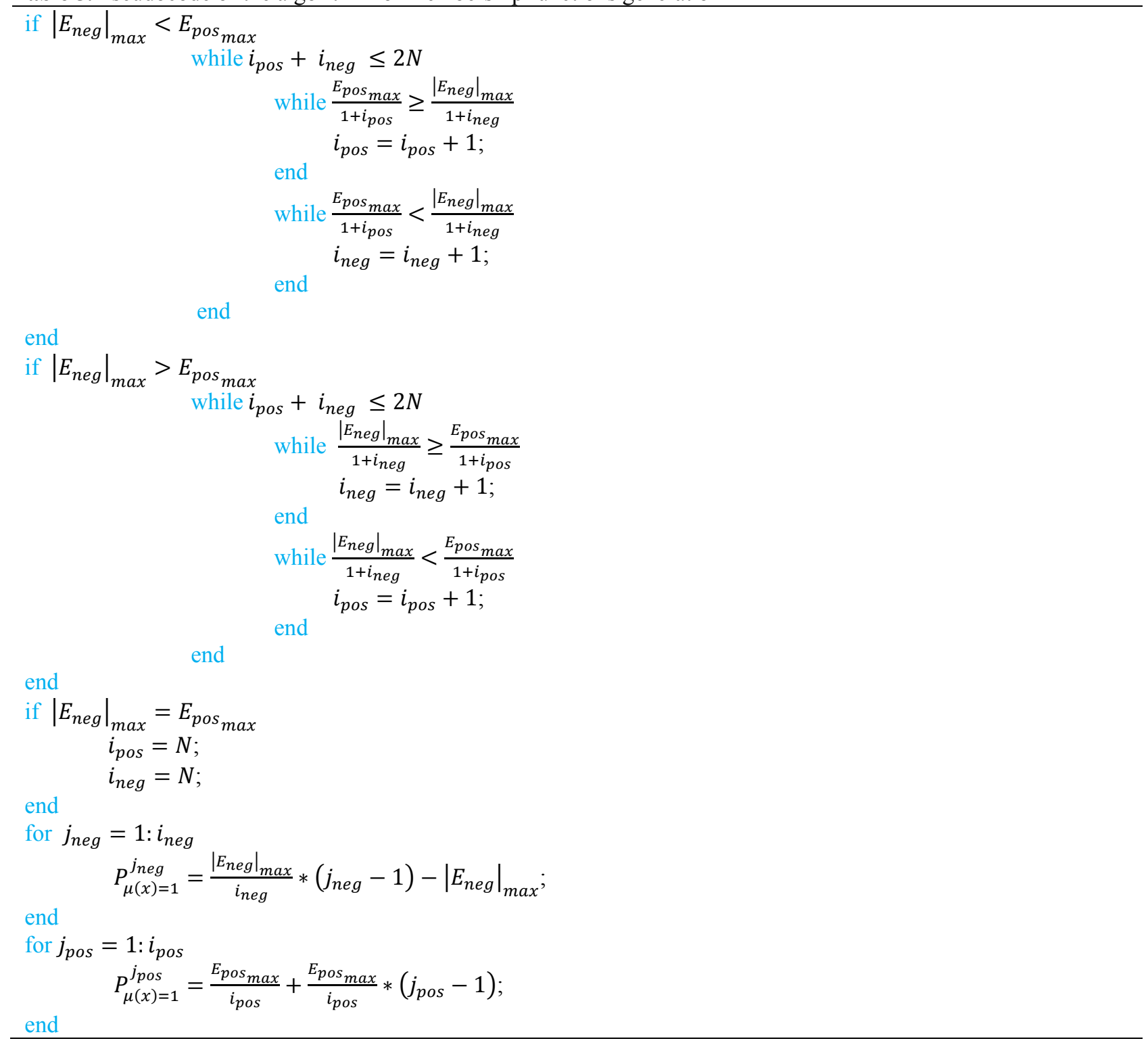

The following notation is valid here. The number of membership functions is denoted as $2 N+1$. A starting point of a variable domain, i.e. the maximum absolute value of the negative error of speed assessment form the sample is $\left|E_{\text {neg }}\right|_{\text {max }}$, while the maximum value of the positive error of 
speed assessment is $E_{\text {pos }}$ max . The number of membership functions on the negative side of the variable domain is $i_{n e g}$, and the number on the positive side is $i_{p o s}$. The position of points with the highest degree of membership on the negative side of the variable domain is $P_{\mu(x)=1}^{j_{n e g}}$, while the same parameter for the positive side is $P_{\mu(x)=1}^{j_{\text {pos }}}$. Since the proposed algorithm finds $2 N$ points with the highest degree of membership at the $x$-axis, there is one more remaining point to be defined. In each case, it is the point where the error in speed assessment is equal to zero. It should be noted that all the mentioned points are the same for both, upper and lower membership functions. When it comes to the points of upper membership functions where $\mu(x)=0$, they are placed at $x$-axis where adjacent fuzzy sets have the highest degree.

After the position of membership functions is determined, the fuzzy sets formed accordingly should be named. In our case, five membership functions describe each input variable, which means that $N=2$. However, the following names of fuzzy sets were used depending on the domain of a variable and position of the points with the highest membership degree: $V E U_{-} S_{i}-$ Assessment is very extremely under $S_{i}, E U_{-} S_{i}$ - Assessment is extremely under $S_{i}, S U_{-} S_{i}$ - Assessment is significantly under $S_{i}, M U_{-} S_{i}-$ Assessment is moderately under $S_{i}, A_{-} S_{i}-$ Assessment is around $S_{i}, M O \_S_{i}-$ Assessment is moderately over $S_{i}, S O \_S_{i}-$ Assessment is significantly over $S_{i}$ and $E O_{-} S_{i}-$ Assessment is extremely over $S_{i}$, where the parameter $S_{i}(i=1,3)$ takes the following values: $S_{1}=30$ $\mathrm{km} / \mathrm{h}, S_{2}=50 \mathrm{~km} / \mathrm{h}$, and $S_{3}=70 \mathrm{~km} / \mathrm{h}$.

An example of how the membership functions for input variables in the case of T2FIS_30 are designed based on the proposed algorithm is shown in Fig. 4. There are four parts a), b), c), and d) describing the variables $x_{1}, x_{4}, x_{7}$, and $x_{10}$, respectively.

On the other hand, the output variable is defined just with three membership functions because the interval that should be covered is relatively small. The reason lies in the fact that the participants were young drivers with a small number of MVCs in their driving experience. Therefore, the values near zero belong to the fuzzy set $S N A$ - Small number of MVCs; values near 3, which is the maximum number of MVCs reported by the participant, are described by the fuzzy set $H N A$ - High number of MVCs; and in the middle of the considered interval, there is the fuzzy set $M N A$ - Middle number of MVCs.

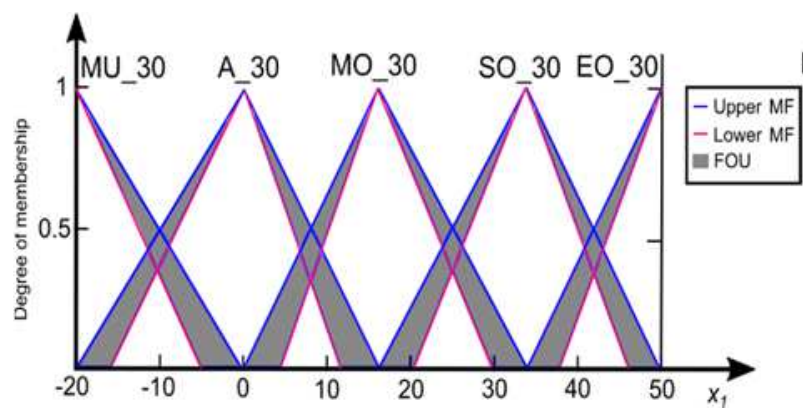

a)

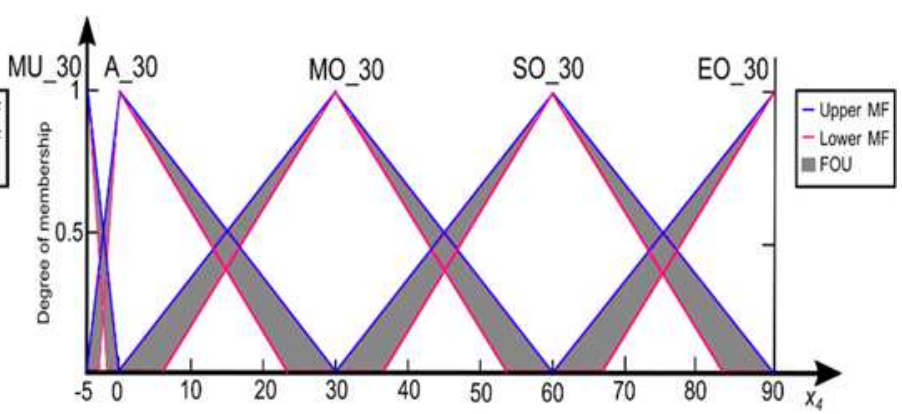

b)

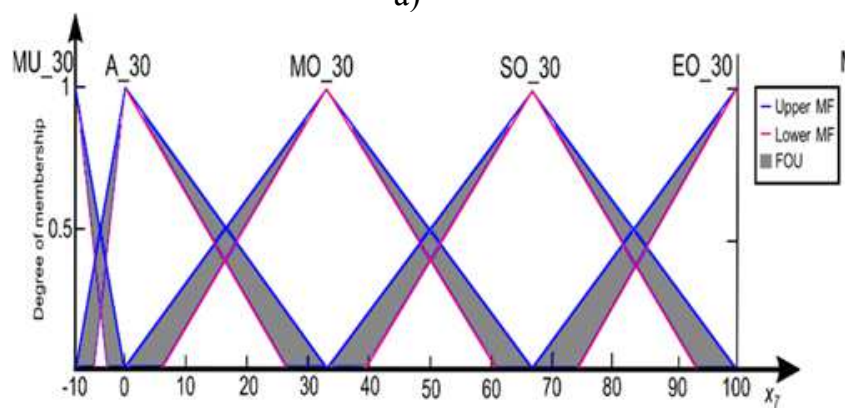

c)

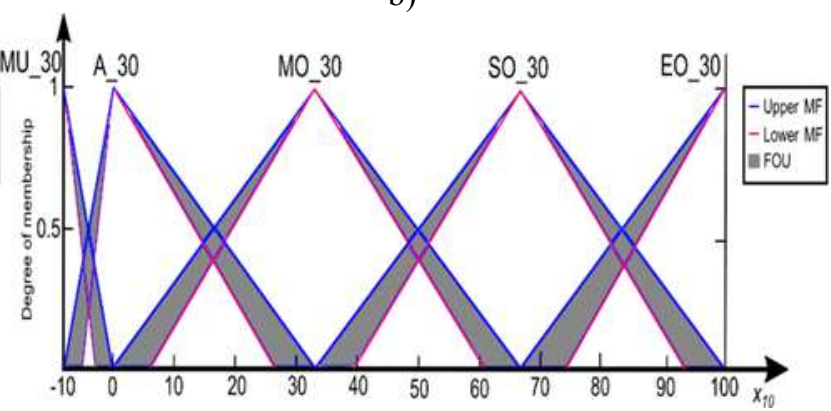

d)

Figure 4. Input variables for T2FIS_30; Part a) variable $x_{1}-$ Front view: $30 \mathrm{~km} / \mathrm{h}$; Part b) variable $x_{4}-$ Rear view: $30 \mathrm{~km} / \mathrm{h}$; Part c) variable $x_{7}-$ Side view: $30 \mathrm{~km} / \mathrm{h}$; Part d) variable $x_{10}-$ Driver's perspective: $30 \mathrm{~km} / \mathrm{h}$ 
After the variables of T2FIS were described by the corresponding fuzzy sets, it was necessary to set the fuzzy rules. Here, we applied the well-known method proposed by Wang and Mendel (1992). This approach is widely used in the literature (Chang, Hieh, and Liao,2005; CubranićDobrodolac et al., 2019, 2020a, 2020b, 2020c; Jovčić et al, 2019).

Wang-Mendel's method consists of two general parts. In the first part, fuzzy rules are generated from the empirical data and the missing rules are added based on expert opinion in the second part. The first part is solved in this paper based on the programming code that is offered in the paper by Čubranić-Dobrodolac et al., 2020a. In this process, depending on the concrete T2FIS category, the specific input-output pairs were taken into consideration as demonstrated in Table 6 . The concrete values of selected inputs and output that are used in the calculation process correspond to the total sample of 178 participants. In practice, many rules generated from the empirical data are the same or conflict which results in the fact that in the concrete cases, from 178 input-output pairs, the number of final rules based on the empirical data is from 23 to 38 . The total number of fuzzy rules in the considered T2FIS categories is 125 and 625, in the case of T2FIS with 3 inputs and 4 inputs, respectively.

To design a complete fuzzy rule base, the authors' logic was based on the assumption of linear interdependence between input and output variables in the following way: if the errors in speed assessments are higher, then the number of experienced MVCs is higher. In the concrete case, for example in T2FIS_30, one of the fuzzy rules would be:

IF $\boldsymbol{x}_{\boldsymbol{I}}$ (Assessment error in Front view - 30km/h) is $\boldsymbol{S O} \boldsymbol{O} \mathbf{3 0}$ (Significantly over $30 \mathrm{~km} / \mathrm{h}$ ) and $\boldsymbol{x}_{\boldsymbol{4}}$ (Assessment error in Rear view - 30km/h) is $\boldsymbol{E} \boldsymbol{O} \_30$ (Extremely over $30 \mathrm{~km} / \mathrm{h}$ ) and $\boldsymbol{x}_{7}$ (Assessment error in Side view - 30km/h) is $\boldsymbol{E} \boldsymbol{O} \_3 \boldsymbol{0}$ (Extremely over $30 \mathrm{~km} / \mathrm{h}$ ) and $\mathrm{km} / \mathrm{h}$ )

$\boldsymbol{x}_{10}$ (Assessment error in Driver's perspective $-30 \mathrm{~km} / \mathrm{h}$ ) is $\mathbf{S O} \mathbf{3 0}$ (Significantly over 30

THEN $y$ (the number of MVCs) is $\boldsymbol{H N A}$ (High number of MVCs).

Table 6. The use of data in a particular fuzzy inference system category

\begin{tabular}{ll}
$\begin{array}{c}\text { T2FIS } \\
\text { Category }\end{array}$ & \multicolumn{1}{c}{ Used input-output data } \\
\hline T2FIS_30 & $\left(x_{1}^{(1)}, x_{4}^{(1)}, x_{7}^{(1)}, x_{10}^{(1)} ; y^{(1)}\right),\left(x_{1}^{(2)}, x_{4}^{(2)}, x_{7}^{(2)}, x_{10}^{(2)} ; y^{(2)}\right), \ldots,\left(x_{1}^{(178)}, x_{4}^{(178)}, x_{7}^{(178)}, x_{10}^{(178)} ; y^{(178)}\right)$ \\
T2FIS_50 & $\left(x_{2}^{(1)}, x_{5}^{(1)}, x_{8}^{(1)}, x_{11}^{(1)} ; y^{(1)}\right),\left(x_{2}^{(2)}, x_{5}^{(2)}, x_{8}^{(2)}, x_{11}^{(2)} ; y^{(2)}\right), \ldots,\left(x_{2}^{(178)}, x_{5}^{(178)}, x_{8}^{(178)}, x_{11}^{(178)} ; y^{(178)}\right)$ \\
T2FIS_70 & $\left(x_{3}^{(1)}, x_{6}^{(1)}, x_{9}^{(1)}, x_{12}^{(1)} ; y^{(1)}\right),\left(x_{3}^{(2)}, x_{6}^{(2)}, x_{9}^{(2)}, x_{12}^{(2)} ; y^{(2)}\right), \ldots,\left(x_{3}^{(178)}, x_{6}^{(178)}, x_{9}^{(178)}, x_{12}^{(178)} ; y^{(178)}\right)$ \\
T2FIS_F & $\left(x_{1}^{(1)}, x_{2}^{(1)}, x_{3}^{(1)} ; y^{(1)}\right),\left(x_{1}^{(2)}, x_{2}^{(2)}, x_{3}^{(2)} ; y^{(2)}\right), \ldots,\left(x_{1}^{(178)}, x_{2}^{(178)}, x_{3}^{(178)} ; y^{(178)}\right)$ \\
T2FIS_R & $\left(x_{4}^{(1)}, x_{5}^{(1)}, x_{6}^{(1)} ; y^{(1)}\right),\left(x_{4}^{(2)}, x_{5}^{(2)}, x_{6}^{(2)} ; y^{(2)}\right), \ldots,\left(x_{4}^{(178)}, x_{5}^{(178)}, x_{6}^{(178)} ; y^{(178)}\right)$ \\
T2FIS_S & $\left(x_{7}^{(1)}, x_{8}^{(1)}, x_{9}^{(1)} ; y^{(1)}\right),\left(x_{7}^{(2)}, x_{8}^{(2)}, x_{9}^{(2)} ; y^{(2)}\right), \ldots,\left(x_{7}^{(178)}, x_{8}^{(178)}, x_{9}^{(178)} ; y^{(178)}\right)$ \\
T2FIS_D & $\left(x_{10}^{(1)}, x_{11}^{(1)}, x_{12}^{(1)} ; y^{(1)}\right),\left(x_{10}^{(2)}, x_{11}^{(2)}, x_{12}^{(2)} ; y^{(2)}\right), \ldots,\left(x_{10}^{(178)}, x_{11}^{(178)}, x_{12}^{(178)} ; y^{(178)}\right)$ \\
\hline
\end{tabular}

Finally, the T2FIS categories should be tested comparing themselves with each other. For this purpose, we use Eq. (1). Cumulative deviation $(C D)$ is a measure that describes how well the performance of T2FIS corresponds to the empirical data. CD is calculated as an absolute value of the difference between the actual number of MVCs experienced by drivers in the sample $y^{(i)}$, and corresponding results of T2FIS that is marked as T2FIS $(i)$. A letter $i$ in the mentioned variables denotes each of 178 participants from the sample. This concept of measuring the performance of FIS categories can be found also in other papers (see Cubranic-Dobrodolac et. al., 2019; Jovcic, et al., 2019).

$$
C D=\sum_{i=1}^{178}\left|y^{(i)}-T 2 F I S(i)\right|
$$




\subsection{The optimization of T2FIS by a BCO metaheuristic algorithm}

BCO metaheuristic was proposed by Lučić, and Teodorović $(2001,2003)$. The essence is that the artificial bees collectively search for the best solution. They independently search the space of permissible solutions, comparing the obtained solutions in particular moments. In the comparison procedure, the quality of the achieved solution impacts the probability of whether a bee will continue its search on its own path or it will follow some other bee. The probability in decision-making is provided to avoid being trapped in local optimums. When a bee starts its search, this part of the algorithm is called forward pass, while the procedure of returning to the hive and comparison of achieved solutions is called backward pass.

The main attributes of the BCO algorithm are the following (Nikolić, \& Teodorović, 2013):

$B$ - the number of bees involved in the search procedure,

$I T$ - the number of iterations,

$N P$ - the number of forward and backward passes in one iteration,

$N C$ - the number of solution changes in one forward pass,

$S$ - the best-known solution.

The application of the BCO algorithm for T2FIS optimization in our case is based on the following principles. Each vertex of upper Membership Functions (MFs) is considered as a parameter $P_{f}(c h)(f=1, N P ; c h=1, N C)$ to be changed $N C$ times in one forward pass. In the same time, when upper MF is changed, the lower MF has changed accordingly, where we followed the principle that points with the maximum degree of membership $(\mu(x)=1)$ for particular MF are the same for upper and lower MF in all changes and the Footprint of Uncertainty (FOU) is relatively similar before and after the change.

After each change of a parameter, the fuzzy rules should be set. This is performed by applying the WM method. When a T2FIS is completely designed, the effects of each change should be tested on the empirical data by applying Eq. (1).

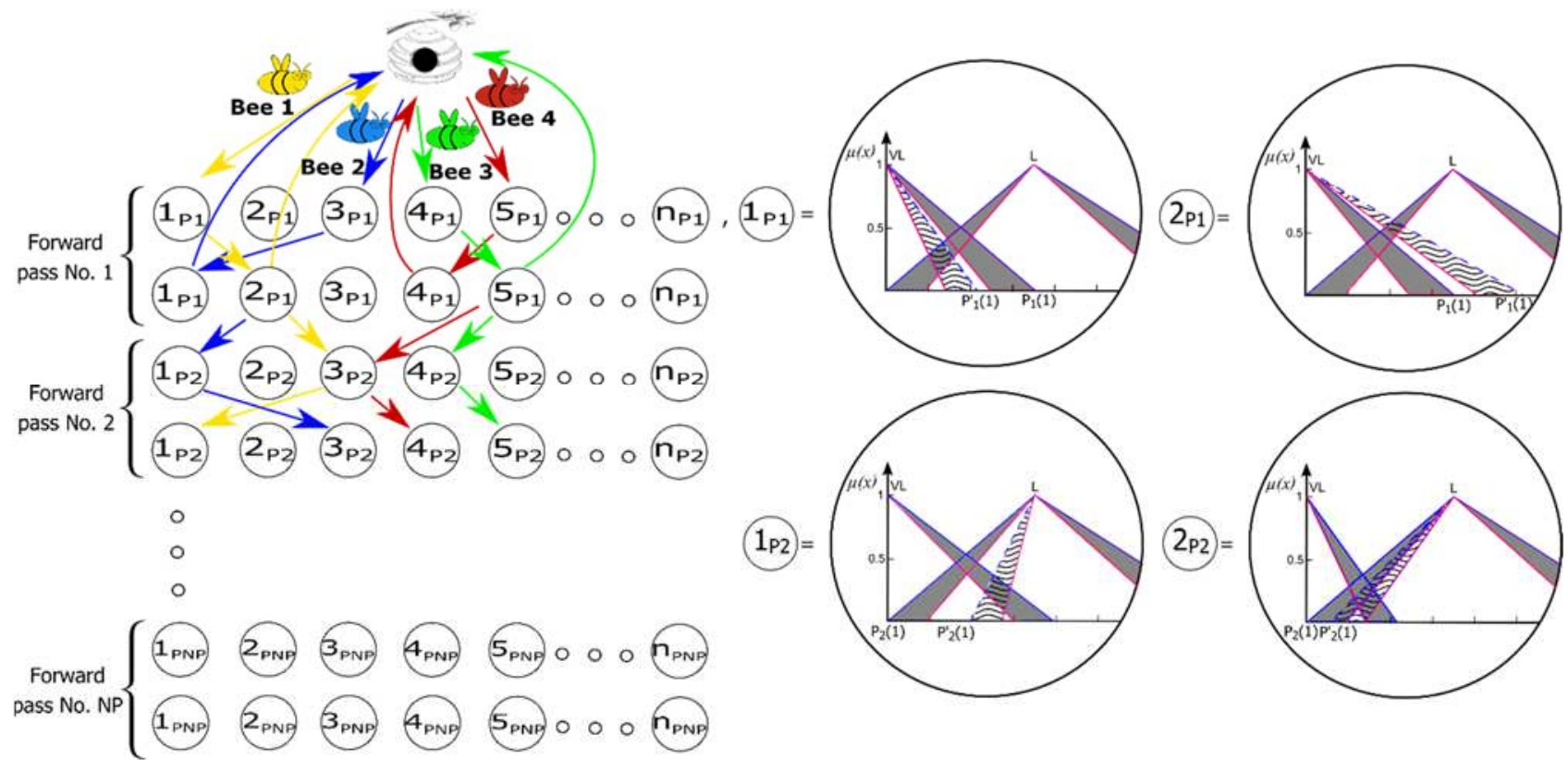

Figure 5. The concept of the BCO algorithm for T2FIS optimization in the case $\mathrm{B}=4, \mathrm{NC}=2$.

The concept of the proposed BCO algorithm is shown in Fig. 5. In our research $N C=5$; however, for the simplicity of illustration, here it is assumed that $N C=2$ which means that in a forward pass there will be two changes of the parameter. Each parameter $P_{f}(c h)$ is changed by the new value $P_{f}^{\prime}(\mathrm{ch})$ according to Eq. (2) and after each change and generation of new fuzzy rules, the performance of newly created T2FIS is evaluated by Eq. (1). 


$$
P_{f}^{\prime}(c h)=P_{f m i n}+\left(P_{f \max }-P_{f \min }\right) * \operatorname{rand}_{f, c h}
$$

$P_{f \min }$ is the minimal value of the parameter $P_{f}, P_{f \max }$ is the maximum value of the parameter $P_{f}$ $(f=1, N P)$, and $\operatorname{rand}_{f, c h}$ is a random number in the interval from 0 to 1 which changes its value $N P$ $\mathrm{x} N C$ times in each iteration $(c h=1, N C)$.

To implement the Eq. (2), it is necessary to set the constraints, i.e. the range where $P_{f}^{\prime}(c h)$ can take the values. Accordingly, we need to define $P_{f \min }$ and $P_{f \max }$. In the following text, the constraints in the case of the first input variable of T2FIS_30 will be presented. The same principle is applied for other variables of this T2FIS and other defined T2FIS structures in this paper. First, the notation used in the constraints should be noticed in Fig. 6. As can be noticed, we use the symbol $R^{u}$ for the parameter of MF that is "right" border of this MF, and $L^{u}$ for the parameter that is "left" border of considered MF. Letter $u$ in the upper index denotes that it is about Upper MF, while the symbols in the lower index determine the MF that the considered parameter describes. The points at X-axis where MF has the maximum degree $(\mu(\mathrm{x})=1)$ is marked with $M_{M F}$, for example $M_{M U_{-} 30}$. In the case of T2FIS_30, the parameters $R_{M U \_30 \_m i n}^{u}, L_{A_{-} 30 \_m i n}^{u}, M_{A_{-} 30 \_m i n}, R_{A_{-} 30 \_m i n}^{u}, L_{M O \_30 \_m i n}^{u}, M_{M O \_30 \_m i n}$, $R_{M O \_30 \_m i n}^{u}, L_{S O \_30 \_m i n}^{u}, M_{S O \_30 \_m i n}, R_{S O \_30 \_m i n}^{u}, L_{E O \_30 \_m i n}^{u} \operatorname{denotes} P_{f m i n}$, while $R_{M U \_30 \_m a x}^{u}$, $L_{A \_30 \_\max }^{u}, M_{A \_30 \_\max }, R_{A_{-} 30 \_\max }^{u}, L_{M O \_30 \_\max }^{u}, M_{M O \_30 \_\max }, R_{M O \_30 \_\max }^{u}, L_{S O \_30 \_\max }^{u}, M_{S O \_30 \_\max }$, $R_{S O \_30 \_ \text {max }}^{u}, L_{E O \_30 \_ \text {max }}^{u}$ represents $P_{\text {fmax }}$.

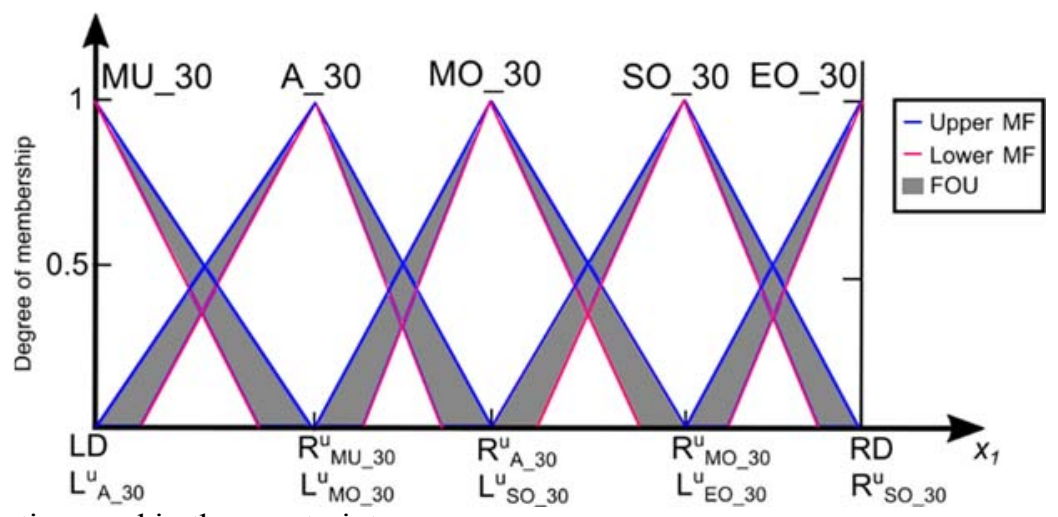

Figure 6. A part of the notation used in the constraints

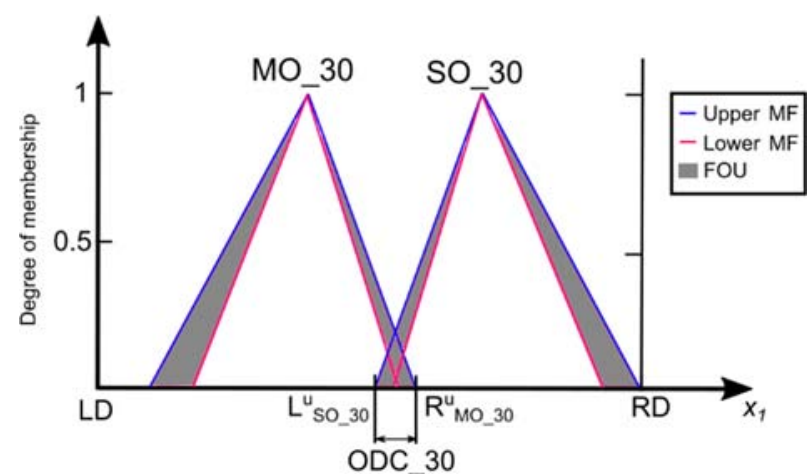

(a)

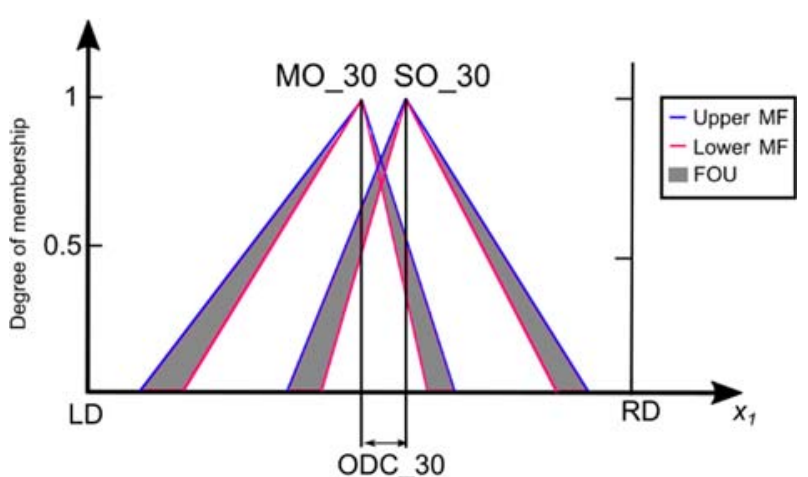

(b)

Figure 7. A presentation of Overlapping and Distance Constant (ODC): (a) the minimum allowed overlapping in the proposed algorithm; (b) the minimum allowed distance between two membership functions for the points with the maximum degree $(\mu(\mathrm{x})=1)$

Besides, another factor that appears in the constraints is $O D C$, representing an overlapping and distance constant. A case when $O D C$ represents the minimum allowed overlapping is presented in part (a) of Fig. 7, while the same value of $O D C$ can be used as the minimum allowed distance 
between two membership functions for the points with the maximum degree $(\mu(x)=1)$ illustrated in the part (b) of Fig. 7. In the proposed algorithm, the value of $O D C$ should be calculated for each variable of T2FIS, by Eq. 3, where $L D$ is the lower border of the domain of the variable, $R D$ is the upper border of the domain of the variable, and $n_{M F}$ is the number of MF that describes the considered variable.

$$
O D C=\frac{R D-L D}{n_{M F}} * 10 \%
$$

The Eq. (3) is set according to the authors' opinion; however, the condition about overlapping can be set also in some other way. Some authors even do not set it in the procedure of MF tuning. For example, Nikolić, et al. (2020) allow the cases with minimal overlapping of MFs, or even the cases where MFs do not even "touch" between themselves, leaving in this way some parts of the variable's domain uncovered by MFs. The authors of the paper Nikolić et al. (2020) accept and perform testing of FIS structures where some parts of variable's domain remain uncovered in their algorithm; however, in the further procedure, during the calculation of the objective function of the considered problem, a penalty is added to discourage the algorithm from keeping these solutions. To avoid this kind of procedure, in this paper we introduce $O D C$ to prevent the unwanted FIS structures from the beginning of the algorithm, by that improving the performance of the algorithm execution.

After the explanation of used notation, the constraints in the case of the first input variable of T2FIS_30, with the aim to calculate $R_{M U_{-} 30}^{u}, L_{A_{-} 30}^{u}, M_{A_{-} 30}, R_{A_{-} 30}^{u}, L_{M O \_30}^{u}, M_{M O \_30}, R_{M O \_30}^{u}, L_{S O \_}^{u}$, $M_{S O \_30}, R_{S O \_30}^{u}, L_{E O \_30}^{u}$, are set in the following way:

For MU_30: $\quad R_{M U_{-} 30 \_\min }^{u}=M_{M U_{-} 30}+O D C_{-} 30$

$R_{M U_{-} 30 \_ \text {max }}^{u}=\left(M_{A_{-} 30}+M_{M O_{-} 30}\right) / 2$.

For A_30: $\quad L_{A_{-} 30 \_ \text {min }}^{u}=L D$;

$L_{A_{-} 30 \_\max 1}^{u}=R_{M U_{-} 30}^{u}-O D C_{-} 30 ; L_{A_{-} 30 \_\max 2}^{u}=M_{A_{-} 30}-O D C_{-} 30$;

$L_{A_{-} 30 \_ \text {max }}^{u}=\min \left(L_{A_{-} 30 \_\max 1}^{u}, L_{A_{-} 30 \_\max 2}^{u}\right)$.

$M_{A_{-} 30 \_\min 1}=L D+2 * O D C_{-} 30 ; M_{A_{-} 30 \_ \text {min } 2}=L_{A_{-} 30}^{u}+O D C_{-} 30$;

$M_{A_{-} 30 \_ \text {min }}=\max \left(M_{A_{-} 30 \_ \text {min } 1}, M_{A_{-} 30 \_ \text {min } 2}\right)$;

$M_{A_{-} 30 \_\max 1}=M_{M O_{-} 30}-2 * O D C_{-} 30 ; M_{A_{-} 30 \_\max 2}=R_{A_{-} 30}^{u}-O D C_{-} 30$;

$M_{A_{-} 30 \_ \text {max }}=\min \left(M_{A_{-} 30 \_\max 1}, M_{A_{-} 30_{-} \max 2}\right)$.

$R_{A_{-} 30 \_\min 1}^{u}=M_{A_{-} 30}+O D C_{-} 30 ; R_{A_{-} 30 \_\min 2}^{u}=L_{M O_{-} 30}^{u}+O D C_{-} 30$;

$R_{A_{-} 30 \_ \text {min }}^{u}=\max \left(R_{A_{-} 30 \_m i n 1}^{u}, R_{A_{-} 30 \_ \text {min } 2}^{u}\right)$;

$R_{A_{-} 30_{-} \max }^{u}=\left(M_{M_{-} 30}+M_{S_{0} \_30}\right) / 2$.

For MO_30: $\quad L_{M O_{-} 30 \_ \text {min }}^{u}=\left(M_{M U_{-} 30}+M_{A_{-} 30}\right) / 2$;

$L_{M O \_30 \_\max 1}^{u}=R_{A_{-} 30}^{u}-O D C_{-} 30 ; L_{M O \_30}^{u} \max 2=M_{M O \_} 30-O D C_{-} 30$;

$L_{M O \_30 \_\max }^{u}=\min \left(L_{M O \_30 \_\max 1}^{u}, L_{M O \_30 \_\max 2}^{u}\right)$.

$M_{M O_{-} 30 \_\min 1}=M_{A_{-} 30}+2 * O D C_{-} 30 ; M_{M O_{-} 30 \_\min 2}=L_{M O_{-} 30}^{u}+O D C_{-} 30$;

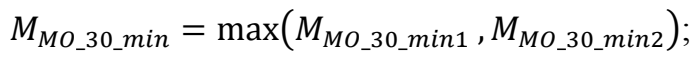

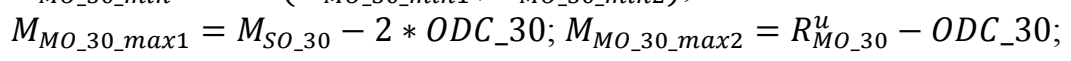

$M_{M O \_30 \_ \text {max }}=\min \left(M_{M O \_30 \_\max 1}, M_{M O \_30 \_\max 2}\right)$.

$R_{M O \_30 \_ \text {min } 1}^{u}=M_{M O \_}$30 $+O D C_{-} 30 ; R_{M O \_30 \_ \text {min } 2}^{u}=L_{S O \_}^{u} 30+O D C_{-} 30 ;$

$R_{M O \_30 \_m i n}^{u}=\max \left(R_{M O \_30 \_m i n 1}^{u}, R_{M O \_30 \_m i n 2}^{u}\right)$;

$R_{M O \_30 \_ \text {max }}^{u}=\left(M_{S O_{-} 30}+R D\right) / 2$.

For SO_30: $\quad L_{S O_{-} 30 \_ \text {min }}^{u}=\left(M_{A_{-} 30}+M_{M O_{-} 30}\right) / 2$;

$L_{S O \_30 \_\max 1}^{u}=R_{M O_{3} 30}^{u}-O D C_{-} 30 ; L_{S O \_30 \_ \text {max } 2}^{u}=M_{S O_{-} 30}-O D C_{-} 30$;

$L_{S O \_30 \_m a x}^{u}=\min \left(L_{S O \_30 \_m a x 1}^{u}, L_{S O \_30 \_}^{u} \max 2\right)$.

$M_{S O_{-} 30 \_\min 1}=M_{M O_{-} 30}+2 * O D C_{-} 30 ; M_{S O_{-} 30 \_\min 2}=L_{S O_{-} 30}^{u}+O D C_{-} 30$; 


$$
\begin{aligned}
& M_{S O \_30 \_m i n}=\max \left(M_{S O \_30 \_m i n 1}, M_{S O \_30 \_m i n 2}\right) \text {; } \\
& M_{S O \_30 \_\max 1}=R D-2 * O D C_{-} 30 ; M_{S O \_30 \_\max 2}=R_{S O \_30}^{u}-O D C_{-} 30 \text {; } \\
& M_{S O \_30 \_\max }=\min \left(M_{S_{0} \_30 \_\max 1}, M_{S O \_30 \_\max 2}\right) \text {. } \\
& R_{S O \_30 \_m i n 1}^{u}=M_{S O \_} 30+O D C_{-} 30 ; R_{S O \_30 \_m i n 2}^{u}=L_{E O \_30}^{u}+O D C_{-} 30 \text {; }
\end{aligned}
$$

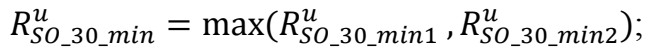

$$
\begin{aligned}
& R_{S O \_30 \text { max }}^{u}=R D \text {. }
\end{aligned}
$$

For EO_30: $\quad L_{E O_{-} 30 \_ \text {min }}^{u}=\left(M_{M O_{-} 30}+M_{S O_{-} 30}\right) / 2$;

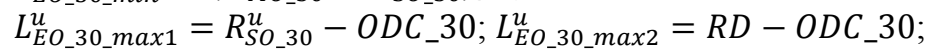

$L_{E O \_}^{u} 0_{-} \max =\min \left(L_{E O_{-} 30 \_\max 1}^{u}, L_{E O_{-} 30 \_ \text {max } 2}^{u}\right)$.

It should be noticed that the concrete values in the set conditions, considering this explained variable and also others in the T2FIS structure, are dynamically changing during the execution of the algorithm. It means that each formed T2FIS in the testing procedure has its conditions that characterize the concrete fuzzy system.

When a bee finishes its forward pass making two changes (because $N C=2$ in Fig. 5), it should decide which of two values will take and bring to the hive for comparison with other bees. This is decided by a certain probability level having in mind the quality of achieved solutions and further by generating a random number and implementing the principle of a roulette wheel.

A principle of bees' solutions comparison is also based on probability. First, a bee should decide to be loyal or not to its obtained solution. If the bee decides not to be loyal to its solution, it chooses which bee of those that are loyal to own solution to follow. In our algorithm, all decisions are based on the principle of the roulette wheel (Marković, 2017); however, some other approach is possible, for example, to make decisions based on a fuzzy inference system (Dell'Orco et al.,2017).

Table 7. Pseudocode of implemented BCO algorithm for T2FIS optimization

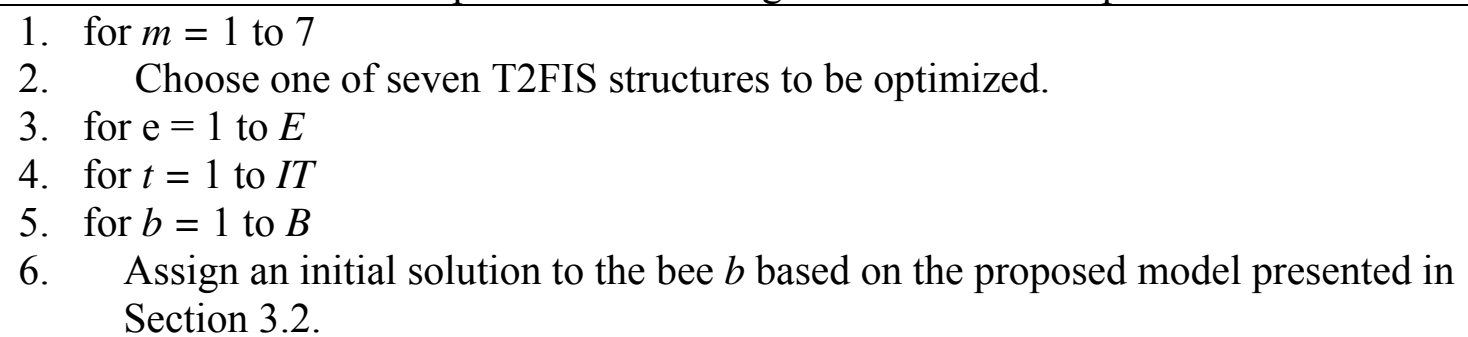

7. for $f=1$ to $N P$

8. for $b=1$ to $B$

9. for $c h=1$ to $N C$

10. Evaluate the performed changes in the solution of the bee $b$. Chose one change considering the obtained values of the objective function.

11. for $b=1$ to $B$

12. Based on the values of the objective function for each bee, decide whether the bee $b$ is loyal to its solution. If the bee $b$ is not loyal, chose the bee to be followed by the bee $b$.

13. Evaluate all solutions and find the best one $S$.

14. Output the best solution for each iteration

15. Sort the best solutions in each experiment.

16. Find Mean of achieved solutions of all experiments per T2FIS structure

In the case of Fig. 5, the Bees 1 and 3 are loyal to their previous solutions, while the Bees 2 and 4 decide to continue their search following the solutions of the Bee 1 and 3, respectively.

The pseudocode of the BCO algorithm applied to optimize T2FISs is shown in Table 7. In the proposed pseudocode, the used symbols are as previously defined (inputs: $B, I T, N P, N C$; output: $S$ ). A case when the proposed algorithm is performed ones, including IT iterations, will be called an 
experiment $(E)$. It is welcome to repeat the experiment more times and to compare the results. In this paper, we defined the value of IT to be 10 and repeated the experiment 8 times for each of the seven different T2FISs $(m)$. To compare the considered T2FISs, we calculated the mean values of solutions obtained in 8 experiments per each iteration and each T2FIS structure.

\section{Results and Discussion}

In the first step, we tested a relationship between seven T2FIS structures. Here, each T2FIS structure is designed as explained in Section 3.2. The testing of each T2FIS is performed on a sample of 178 young drivers. We selected the young drivers as participants because they are particularly jeopardized road users; as previously stated, for the age of $15-29$, MVCs are the leading cause of death globally. The considered sample included the drivers aged from 19 to 22 years old. There were 99 male and 79 female participants.

The results of the proposed methodology for forming T2FIS structures are shown in Fig. 8 . Since the aim is a minimization of the cumulative deviation of T2FIS results from the empirical data, it can be concluded that the best result is achieved by T2FIS_R $(C D=107.60)$. It is a T2FIS structure that implies the estimation of various speed levels of the vehicle mowing away, i.e. it is about a rear view of the considered vehicle. The second-best result is of T2FIS_D $(C D=110.43)$. In this case the speed levels were assessed from the driver's seat perspective. These results lead to the conclusion that the drivers whose speed perception of vehicles in front of them, as well as, the perception of own vehicle speed is poor, are more prone to experience an MVC. To validate this conclusion, the optimization of each T2FIS structure is performed by the proposed BCO based algorithm.

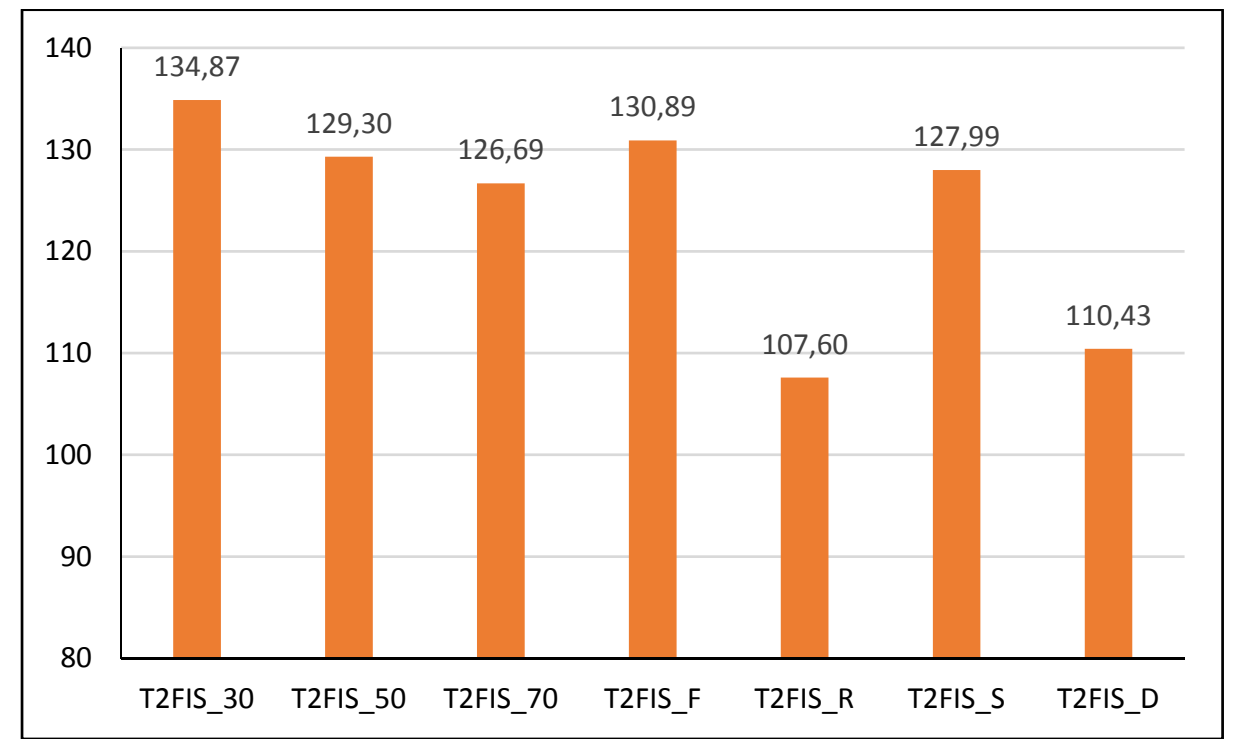

Figure 8. The initial results of testing different T2FIS structures - the obtained CD values

The simulation results based on the implementation of BCO metaheuristic are shown in Fig. 9. Each curve in Fig. 9 represents the results of a T2FIS structure. By analyzing the total number of 80 simulations per each T2FIS structure, i.e. by considering the mean of the best solutions in 8 experiments with 10 simulations, T2FIS_R achieved the best average result. The mentioned mean value of the best $C D$ results of T2FIS_R from 8 experiments is equal to 96.7863 . This leads to the conclusion that T2FIS_R can be used as a very good predictor of MVCs. If we transfer this experiment to the real situation in traffic, it could be said that drivers who misjudge the speed of the vehicle in front of them have an increased risk of MVCs. 


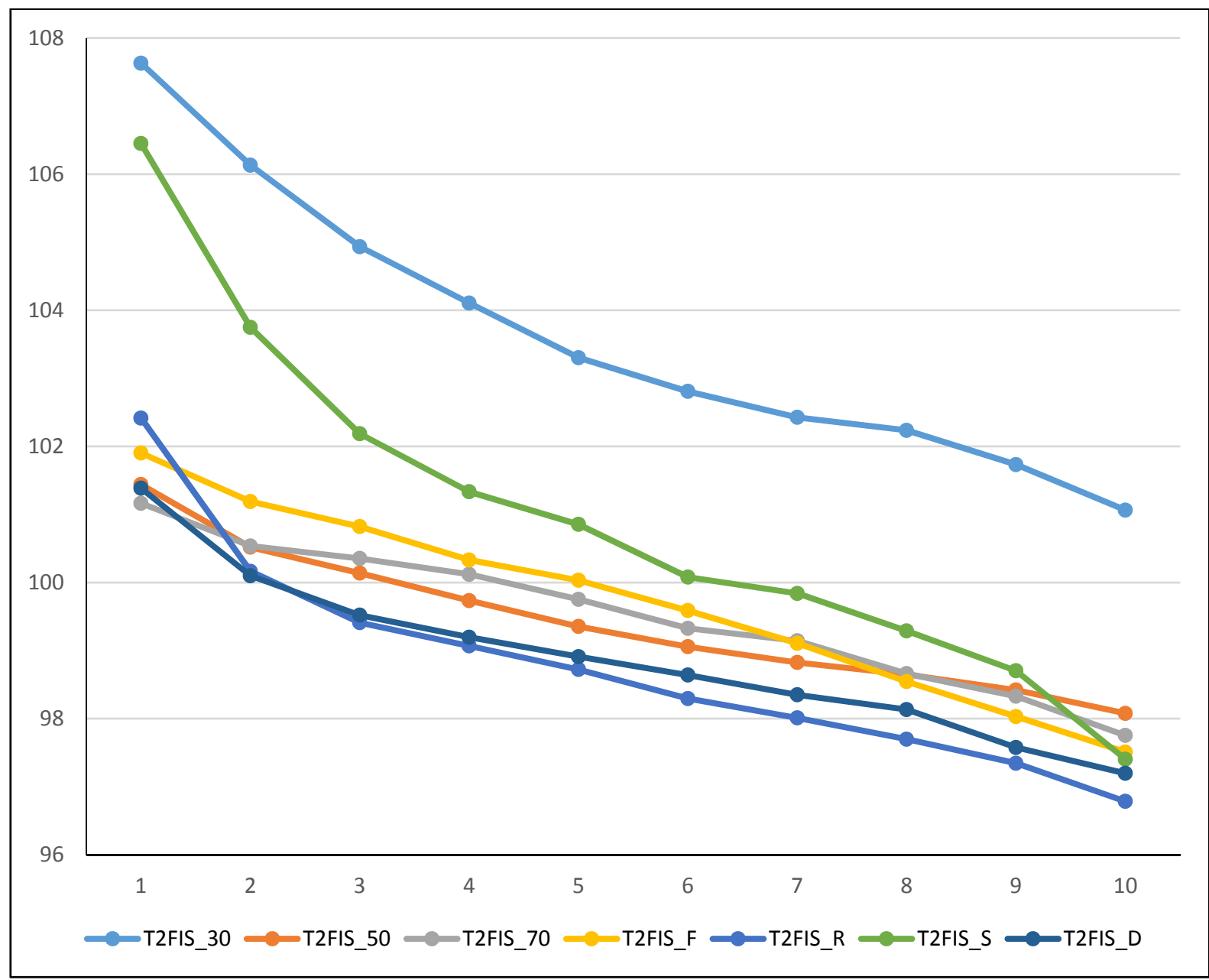

Figure 9. The results of different T2FIS structures optimization - mean values of 8 experiments

By considering all the performed 560 simulations, the best-found T2FIS is T2FIS_D where $C D=96.0294$ (Table 8). Therefore, the problem of perception of the own vehicle speed is proved to be the most important indicator of experiencing MVC.

Table 8. The best solutions per T2FIS category

\begin{tabular}{cccc}
\hline $\begin{array}{c}\text { Name of T2FIS } \\
\text { category }\end{array}$ & $\begin{array}{c}\text { CD value of the best- } \\
\text { found T2FIS }\end{array}$ & $\begin{array}{c}\text { Deviation from the } \\
\text { total best T2FIS }\end{array}$ & $\begin{array}{c}\text { Execution time for 80 } \\
\text { iterations [min] }\end{array}$ \\
\hline T2FIS_30 & 100.3152 & 4.2858 & 2440 \\
T2FIS_50 & 97.7290 & 1.6996 & 2440 \\
T2FIS_70 & 96.9951 & 0.9657 & 2440 \\
T2FIS_F & 96.6310 & 0.6016 & 728 \\
T2FIS_R & 96.2422 & 0.2128 & 728 \\
T2FIS_S & 96.0513 & 0.0219 & 728 \\
T2FIS_D & 96.0294 & 0 & 728 \\
\hline Total & & & $\mathbf{1 0 2 3 2}$ \\
\hline
\end{tabular}

Since two T2FIS structures, T2FIS_R and T2FIS_D appeared to be the most convenient tools for describing a relationship between the considered variables in each of them and the number of MVCs, we performed the t-test to determine a relationship between these two T2FIS structures, as well as the relationship between all the considered T2FIS structures. The results of the t-test are shown in Table 9. Considering T2FIS_R and T2FIS_D, as the best-found T2FIS structures, there is no statistical difference between the two of them. However, if we consider each of these two T2FIS structures individually in relation to other structures, there is a significant difference between each of them and all others $(p<0.05)$. This confirms the conclusion that drivers who misjudge the speed of the vehicle in front of them and own speed, have an increased risk of MVCs. Additionally, these two 
phenomena of speed perception can be used as convenient indicators for the assessment of driver propensity for MVCs.

Table 9. The difference between average CD values per T2FIS tested by paired t-test

\begin{tabular}{lcccccc}
\hline & T2FIS_30 & T2FIS_50 & T2FIS_70 & T2FIS_F & T2FIS_R & T2FIS_S \\
\hline T2FIS_30 & - & & & & & \\
T2FIS_50 & $.000^{*}$ & - & & & \\
T2FIS_70 & $.000^{*}$ & .297 & - & & \\
T2FIS_F & $.000^{*}$ & .088 & .128 & - & & \\
T2FIS_R & $.000^{*}$ & $.011^{*}$ & $.012^{*}$ & $.001 *$ & - & - \\
T2FIS_S & $.000^{*}$ & $.013^{*}$ & $.019^{*}$ & $.014^{*}$ & $.000^{*}$ & $.001^{*}$ \\
T2FIS_D & $.000^{*}$ & $.000^{*}$ & $.000^{*}$ & $.000^{*}$ & .442 & \\
\hline $\mathrm{p}<0.05$ & & & & & &
\end{tabular}

If we consider a T2FIS which describes the empirical data in the worst way, it is T2FIS_30. This data points to the conclusion that if the drivers have a problem with the assessment of lower speeds, it will not significantly affect their safety, i.e. to the participation in MVCs. Further, T2FIS_50 describes the empirical data better than T2FIS_30, and T2FIS_70 even more better. By this, it is possible to conclude that the drivers who misjudge the higher speeds are more likely to participate in MVCs compared to drivers who have a problem with the estimation of lower speeds.

The exact best values that each T2FIS structure achieved are presented in Table 8. Here are also the execution times. The T2FIS structures composed of three input variables take 728 minutes for 80 iterations ( 8 experiments with 10 iterations). To perform the calculations in the case of T2FIS with four input variables, the computer needs 2440 minutes. Therefore, the total execution time is 10232 minutes, which corresponds to 7 days, two hours, and 32 minutes.

At the level of seven considered T2FIS structures, the average improvement of the values of the objective function is $21.17 \%$ (Table 10). This indicates that the proposed optimization algorithm based on the BCO metaheuristic significantly improves the performance of the initial T2FIS structures.

Table 10. A relationship between the initial and the best solutions per T2FIS category

\begin{tabular}{|c|c|c|c|}
\hline $\begin{array}{c}\text { Name of T2FIS } \\
\text { category }\end{array}$ & $\begin{array}{l}\text { CD value of the initial } \\
\text { formed T2FIS }\end{array}$ & $\begin{array}{l}\text { CD value of the } \\
\text { best-found T2FIS }\end{array}$ & $\begin{array}{c}\text { Achieved improvement } \\
{[\%]}\end{array}$ \\
\hline T2FIS_30 & 134.8742 & 100.3152 & 25.62 \\
\hline T2FIS_50 & 129.3012 & 97.7290 & 24.42 \\
\hline T2FIS_70 & 126.6896 & 96.9951 & 23.44 \\
\hline T2FIS F & 130.8939 & 96.6310 & 26.18 \\
\hline T2FIS_R & 107.6026 & 96.2422 & 10.56 \\
\hline T2FIS_S & 127.9885 & 96.0513 & 24.95 \\
\hline T2FIS_D & 110.4311 & 96.0294 & 13.04 \\
\hline Mean & & & 21.17 \\
\hline
\end{tabular}

Since the best-found T2FIS can be used also as a decision-making tool, to assess different drivers about their propensity for MVCs based on their abilities related to speed perception, it is useful to demonstrate this T2FIS. T2FIS_D structure that gives the best result is shown in Fig. 10. It can be used for various purposes in the field of traffic safety.

According to the Road Traffic Safety Agency (2020), the data that refer to the Republic of Serbia and the year 2019 indicate that from MVCs with deaths, there are $38.5 \%$ of MVCs with at least two vehicles where the cause might be related to a poor speed perception. Some of the representatives of the mentioned MVCs are the cases where a minimum of two vehicles are moving in the same direction, such as the rear-end collision, merging into traffic, turning left or right in front of other vehicle, etc. The mentioned type of MVC is the most frequently reported type of MVC (46.6\%) among the participants in our research who experienced an MVC. 


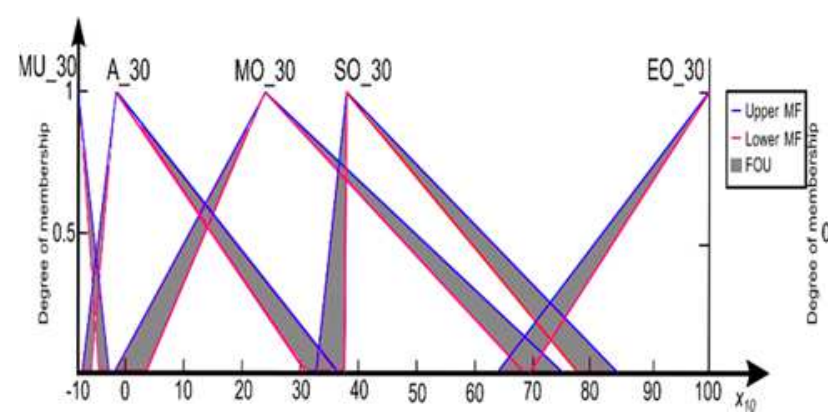

a)

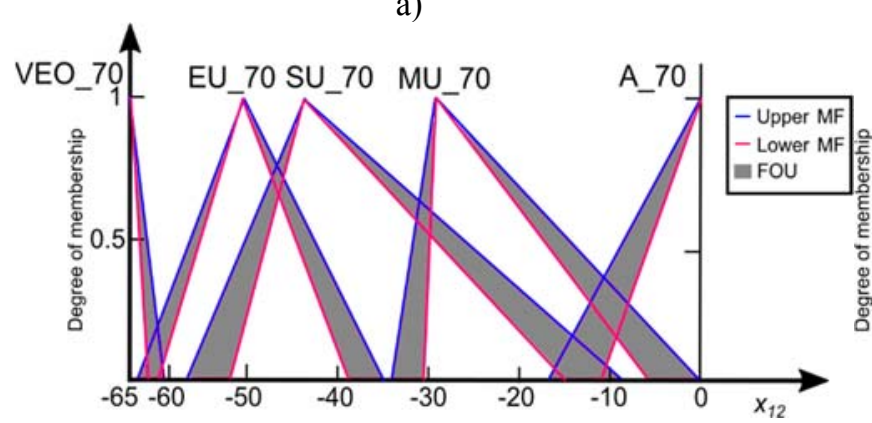

c)

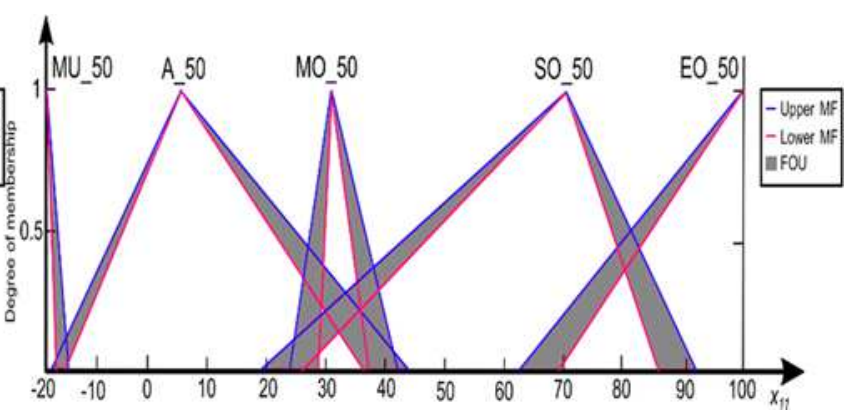

b)

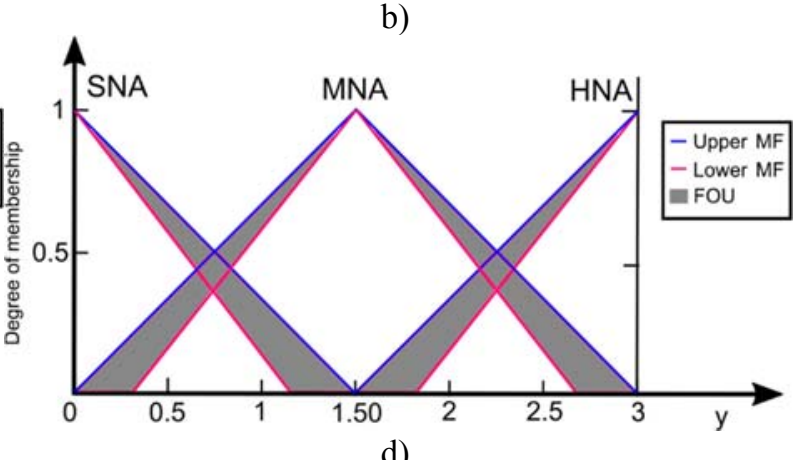

d)

Figure 10. Input and output variables for T2FIS_D after optimization procedure; Part a) variable $x_{10}$ - Driver's perspective: $30 \mathrm{~km} / \mathrm{h}$; Part b) variable $x_{11}$ - Driver's perspective: $50 \mathrm{~km} / \mathrm{h}$; Part c) variable $x_{12}$ - Driver's perspective: $70 \mathrm{~km} / \mathrm{h} ;$ Part d) variable $y$ - The number of motor vehicle crashes

Our results are in line with the findings of the Road Traffic Safety Agency, indicating that drivers who misjudge their own speed and the speed of the vehicle in front of them, have a higher risk of participating in MVCs. These findings could be used for preventive actions and improvement of traffic safety, primarily through the education of attendants in driving schools or by adequate professional drivers' recruitment.

\section{Conclusion}

In this paper, the main goal was to examine how a speed perception of a driver's vehicle or other vehicles on the road influences the occurrence of MVCs. The data were collected in the driving history questionnaire and by twelve types of experiments in the driving simulator. Based on these data, seven T2FIS structures were tested to conclude what type of speed perception has the highest impact on MVCs occurrence. The aim was to conclude which of T2FIS structures describe the empirical data in the best way, which is performed by the proposed BCO based algorithm.

Accordingly, the conclusion was reached about the most convenient technique to assess the driver propensity for MVCs based on testing their speed perception capability. The result indicates that drivers who misjudge the speed of the vehicle they are looking from the rear side, as well as the own vehicle speed, have the highest likelihood of participation in MVCs. This conclusion may be very useful in educational procedures to improve traffic safety.

Since the proposed model is based on the implementation of fuzzy logic, it is also particularly convenient in the case when the researcher would like to offer the participants a possibility to express their speed appraisals by using descriptive statements instead of crisp numbers. Type-2 fuzzy logic systems that we used in the proposed model appear to be more capable of handling problems with high uncertainties, comparing to Type-1 fuzzy systems, and their use in the case of speed estimation is very convenient.

MVCs with the participation of at least two vehicles, where a poor speed assessment can be assigned as its cause are the most common type of MVCs reported in the group of participants in this research (46.6\%). These results are in line with the settings of this study so that drivers who misjudge their own vehicle speed and the speed of the vehicle in front of them have a higher risk of participation in an MVC. Such findings should be used for preventive actions and improvement of traffic safety, 
primarily through the education of attendants in driving schools. For solving the identified problem in traffic safety, a driving simulator can be used. In this way, the future drivers can gain experience in the assessment of their own speed, and also the speed of the vehicle in front. This training would be in a safe environment, on the simulator; however, the benefits could be expected in the real world.

A limitation of this study is related to the considered sample. We tested just the drivers aged from 19 to 22 because it is the most vulnerable group on the road. Further research would be welcome to cover the drivers of all ages as well as different vehicle categories and colors, different test speed ranges, different road weather conditions (cloudy, raining, foggy conditions, etc.). However, the obtained conclusions are very inspiring for the creation of appropriate programs in the field of road traffic safety. The best-found T2FIS can be considered as a decision-making tool that gives information about someone's propensity for MVCs based on an assessment of the speed perception capabilities. The proposed examinations can be used, besides some other testing, in the recruitment procedures for professional drivers to select the drivers with a lower propensity for MVCs. Furthermore, the rehabilitation programs for drivers with traffic law offenses or drivers with an elevated number of MVCs in their driving history can be improved by training of speed perception capabilities.

\section{Declarations}

\section{Ethical approval}

The Faculty ethics committee approved this study and all procedures performed in this study involving human participants were in accordance with the 1964 Helsinki declaration and its later amendments or comparable ethical standards. The participants received no funding for participation in the interview.

\section{Funding details}

There is no funding to report.

\section{Conflict of interest}

The authors declare that they have no conflict of interest.

\section{Informed Consent}

Verbal informed consent was obtained prior to the interview for each of 178 participants in this research.

\section{Authorship contributions}

M.Č.-D.: Conceptualization, Methodology, Formal analysis, Investigation, Resources, Writing Original Draft. L.ŠS.: Methodology, Resources, Supervision, Project Administration. S.Č.: Validation, Investigation, Supervision. A.T.: Conceptualization, Methodology, Formal analysis, Investigation, Writing - Original Draft. M.D.: Data Curation, Software.

\section{References}

Aarts, L., \& Van Schagen, I. (2006). Driving speed and the risk of road crashes: A review. Accident Analysis \& Prevention, 38(2), 215-224. https://doi.org/10.1016/j.aap.2005.07.004

Abd Ali, J., Hannan, M.A., Mohamed, A., Jern, K.P., \& Abdolrasol, M.G. (2020). Implementation of DSP-based optimal fuzzy logic speed controller for IM drive using quantum lightning search algorithm, Measurement, 153, 107372. https://doi.org/10.1016/j.measurement.2019.107372

Ab Talib, M. H., Mat Darus, I. Z., \& Mohd Samin, P. (2019). Fuzzy logic with a novel advanced firefly algorithm and sensitivity analysis for semi-active suspension system using magnetorheological damper. Journal of Ambient Intelligence and Humanized Computing, 10(8), 32633278. https://doi.org/10.1007/s12652-018-1044-4 
Ajithapriyadarsini, S., Mary, P. M., \& Iruthayarajan, M. W. (2019). Automatic generation control of a multi-area power system with renewable energy source under deregulated environment: adaptive fuzzy logic-based differential evolution (DE) algorithm. Soft Computing, 23(22), 12087-12101. https://doi.org/10.1007/s00500-019-03765-2

Aldair, A. A., Rashid, A. T., Rashid, M. T., \& Alsaedee, E. B. (2019). Adaptive Fuzzy Control Applied to Seven-Link Biped Robot Using Ant Colony Optimization Algorithm. Iranian Journal of Science and Technology, Transactions of Electrical Engineering, 43(3), 797-811. https://doi.org/10.1007/s40998-019-00201-X

Allen, M. J., \& Clark, J. R. (1964). Automobile running lights-a research report. Optometry and Vision Science, 41(5), 293-315.

Al-Rukaibi, F., AlKheder, S., AlOtaibi, N., \& Almutairi, M. (2020). Traffic crashes cost estimation in Kuwait. International Journal of Crashworthiness, 25(2), 203-212. https://doi.org/10.1080/13588265.2019.1567966

Ashraf, I., Hur, S., Shafiq, M., \& Park, Y. (2019). Catastrophic factors involved in road accidents: Underlying causes and descriptive analysis. PloS one, 14(10). https://doi.org/10.1371/journal.pone.0223473

Azizi, M., Ghasemi, S. A. M., Ejlali, R. G., \& Talatahari, S. (2019). Optimal tuning of fuzzy parameters for structural motion control using multiverse optimizer. The Structural Design of Tall and Special Buildings, 28(13), e1652. https://doi.org/10.1002/tal.1652

Bassani, M., Rossetti, L., \& Catani, L. (2020). Spatial analysis of road crashes involving vulnerable road users in support of road safety management strategies. Transportation Research Procedia, 45, 394-401. https://doi.org/10.1016/j.trpro.2020.03.031

Ben-Bassat, T., \& Shinar, D. (2011). Effect of shoulder width, guardrail and roadway geometry on driver perception and behavior. Accident Analysis \& Prevention, 43(6), 2142-2152. https://doi.org/10.1016/j.aap.2011.06.004

Bıçaksız, P., Öztürk, İ., \& Özkan, T. (2019). The differential associations of functional and dysfunctional impulsivity with driving style: A simulator study. Transportation Research Part F: Traffic Psychology and Behaviour, 63, 1-11. https://doi.org/10.1016/j.trf.2019.02.011

Blaauw, G. J. (1982). Driving experience and task demands in simulator and instrumented car: a $\begin{array}{llll}\text { validation } \quad \text { study. } & \text { Human }\end{array}$ https://doi.org/10.1177/001872088202400408

Blana, E. (1997). The Pros and Cons of Validating Simulators Regarding Driving Behavior. In Driving Simulation Conference (Vol. 97, pp. 125-135).

Bucsuházy, K., Matuchová, E., Zůvala, R., Moravcová, P., Kostíková, M., \& Mikulec, R. (2020). Human factors contributing to the road traffic accident occurrence. Transportation Research Procedia, 45, 555-561. https://doi.org/10.1016/i.trpro.2020.03.057

Boot, W. R., Charness, N., Mitchum, A., Roque, N., Stothart, C., \& Barajas, K. (2015). Driving Simulator Studies of the Effectiveness of Countermeasures to Prevent Wrong-Way Crashes (No. BDV30-977-10). Florida. Dept. of Transportation.

Chai, C., Wong, Y.D., Wang, X.S. (2017). Safety evaluation of driver cognitive failures and driving errors on right-turn filtering movement at signalized road intersections based on Fuzzy Cellular Automata (FCA) model. Accident Analysis and Prevention, 104, 156-164. https://doi.org/10.1016/j.aap.2017.04.026

Chang, P. C., Hieh, J. C., \& Liao, T. W. (2005). Evolving fuzzy rules for due-date assignment problem in semiconductor manufacturing factory. Journal of Intelligent Manufacturing, 16(4-5), 549557. https://doi.org/10.1007/s10845-005-1663-4

Chouksey, A., Awasthi, S., \& Singh, S. K. (2020). Fuzzy cognitive network-based maximum power point tracking using a self-tuned adaptive gain scheduled fuzzy proportional integral derivative controller and improved artificial neural network-based particle swarm optimization. Fuzzy Sets and Systems, 381, 26-50. https://doi.org/10.1016/j.fss.2019.02.007

Chu, P.Z., Yu, Y., Dong, D.Y., Lin, H. \& Yuan, J.J. (2020). NSGA-II-Based Parameter Tuning Method and GM(1,1)-Based Development of Fuzzy Immune PID Controller for Automatic 
Train Operation System. Mathematical Problems in Engineering, 3731749. https://doi.org/10.1155/2020/3731749

Cicevic, S., Trifunovic, A., Mitrovic, S., \& Nešic, M. (2017). The usability analysis of a different presentation media design for vehicle speed assessment. In Ergonomic Design and Assessment of Products and Systems.

Colombet, F., Paillot, D., Mérienne, F., \& Kemeny, A. (2011). Visual scale factor for speed perception. Journal of Computing and Information Science in Engineering, 11(4). https://doi.org/10.1115/1.4005449

Costa, L. R., Rauen, M. S., \& Fronza, A. B. (2020). Car speed estimation based on image scale factor. Forensic Science International, 110229. https://doi.org/10.1016/j.forsciint.2020.110229

Čubranić-Dobrodolac, M., Molková, T., \& Švadlenka, L. (2019). The Impact of Road Characteristics Assessment on the Traffic Accidents Occurrence. The Proceedings of International Scientific Conference on Information Technology and Data Related Research - Sinteza 2019, Belgrade, Serbia, 26-31, https://doi.org/10.15308/Sinteza-2019-26-31

Čubranić-Dobrodolac, M., Švadlenka, L., Čičević, S., \& Dobrodolac, M. (2020a). Modelling driver propensity for traffic accidents: a comparison of multiple regression analysis and fuzzy approach, International Journal of Injury Control and Safety Promotion, 27(2), 156-167. https://doi.org/10.1080/17457300.2019.1690002

Čubranić-Dobrodolac, M., Švadlenka, L., Čičević, S., \& Trifunović, A. (2020b). Using the Interval Type-2 Fuzzy Inference Systems to Determine a Relationship Between the Road Characteristics Assessment and Road Traffic Accidents. The Proceedings of International Scientific Conference on Information Technology and Data Related Research - Sinteza 2020, Belgrade, Serbia, 227-232. https://doi.org/10.15308/Sinteza-2020-227-232

Čubranić-Dobrodolac, M., Švadlenka, L., Čićević, S., Trifunović, A. \& Dobrodolac, M. (2020c). Using the interval Type-2 fuzzy inference systems to compare the impact of speed and space perception on the occurrence of road traffic accidents, Mathematics, 8(9), 1548. https://doi.org/10.3390/math8091548

Dahlstedt, S., \& Rumar, K. (1973). Vehicle colour and front conspicuity in some simulated rural traffic situations. Department of Psychology, University of Uppsala, Sweden.

Dell'Orco, M., Marinelli, M., \& Altieri M.G. (2017). Solving the gate assignment problem through the Fuzzy Bee Colony Optimization, Transportation Research Part C: Emerging Technologies, 80, 424-438. https://doi.org/10.1016/j.trc.2017.03.019

Dimitriou, L., \& Vlahogianni, E.I. (2015). Fuzzy modeling of freeway accident duration with rainfall and traffic flow interactions. Analytic Methods in Accident Research, 5-6, 59-71. https://doi.org/10.1016/j.amar.2015.04.001

Dingus, T. A., Guo, F., Lee, S., Antin, J. F., Perez, M., Buchanan-King, M., \& Hankey, J. (2016). Driver crash risk factors and prevalence evaluation using naturalistic driving data. Proceedings of the National Academy of Sciences, 113(10), 2636-2641. https://doi.org/10.1073/pnas.1513271113

El-Gendy, E. M., Saafan, M. M., Elksas, M. S., Saraya, S. F., \& Areed, F. F. G. (2020). Applying hybrid genetic-PSO technique for tuning an adaptive PID controller used in a chemical process. Soft Computing, 24(5), 3455-3474. https://doi.org/10.1007/s00500-019-04106-Z

Elias, N., \& Mat Yahya, N. (2020). Fast response fuzzy logic controller optimized by bats sonar algorithm. SN Applied Sciences, 2(2). https://doi.org/10.1007/s42452-020-1993-Z

ETSC. (2020). Road deaths in the European Union - latest data. European Transport Safety Council, Belgium. https://etsc.eu/euroadsafetydata/ Accessed 23 April 2020.

Fildes, B \& Lee, S.J. (1993). The Speed Review: Road Environment, Behavior, Speed Limits, Enforcement and Crashes. MUARC, for Federal Office of Road Safety (FORS) and Road Safety Bereau, Roads and Traffic Authority NSW (RSB).

Gitelman, V., Doveh, E., \& Bekhor, S. (2017). The relationship between free-flow travel speeds, infrastructure characteristics and accidents, on single-carriageway roads. Transportation Research Procedia, 25, 2026-2043. https://doi.org/10.1016/j.trpro.2017.05.398 
Gonzales, M. M., Dickinson, L. M., DiGuiseppi, C., \& Lowenstein, S. R. (2005). Student drivers: a study of fatal motor vehicle crashes involving 16-year-old drivers. Annals of Emergency Medicine, 45(2), 140-146. https://doi.org/10.1016/j.annemergmed.2004.08.039

Guillaume, S. (2001). Designing fuzzy inference systems from data: An interpretability-oriented review. IEEE Transactions on Fuzzy Systems, 9(3), 426-443. https://doi.org/10.1109/91.928739

Hussain, Q., Alhajyaseen, W. K., Pirdavani, A., Reinolsmann, N., Brijs, K., \& Brijs, T. (2019). Speed perception and actual speed in a driving simulator and real-world: A validation study. Transportation research part F: traffic psychology and behaviour, 62, 637-650. https://doi.org/10.1016/j.trf.2019.02.019

Hussain, Q., Almallah, M., Alhajyaseen, W. K., \& Dias, C. (2020). Impact of the geometric field of view on drivers' speed perception and lateral position in driving simulators. Procedia Computer Science, 170, 18-25. https://doi.org/10.1016/j.procs.2020.03.005

Jang, J.-S.R. (1993). ANFIS: adaptive-network-based fuzzy inference system. IEEE Transactions on Systems, Man and Cybernetics, 23(3), 665-685. https://doi.org/10.1109/21.256541

Jannusch, T., Völler, M., Murphy, F., \& Mullins, M. (2020). A new version of the Behaviour of Young Novice Drivers Scale (BYNDS). Insights from a randomised sample of 700 German young novice drivers. Accident Analysis \& Prevention, 145, 105622. https://doi.org/10.1016/j.aap.2020.105622

Janssen, W. H., De Ridder, S., Brouwer, R. F. T., Thomson, R., Fagerlind, H., Lanner, G., ... \& Papi, J. (2006). Roadside infrastructure for safer European roads. https://pdfs.semanticscholar.org/15d9/fba399824ceab3b468e6aa80d691ad15da93.pdf?.ga=2. 58419369.2003852554.1590178541-249198926.1572252379 Accessed 23 April 2020.

Jovčić, S., Průša, P., Dobrodolac, M., Švadlenka, L. (2019). A Proposal for a Decision-Making Tool in Third-Party Logistics (3PL) Provider Selection Based on Multi-Criteria Analysis and the Fuzzy Approach. Sustainability, 11(15):4236. https://doi.org/10.3390/su11154236

Karar, M. E., El-Garawany, A. H., \& El-Brawany, M. (2020). Optimal adaptive intuitionistic fuzzy logic control of anti-cancer drug delivery systems. Biomedical Signal Processing and Control, 58, 101861. https://doi.org/10.1016/j.bspc.2020.101861

Kummetha, V. C., Kondyli, A., Chrysikou, E. G., \& Schrock, S. D. (2020). Safety analysis of work zone complexity with respect to driver characteristics-A simulator study employing performance and gaze measures. Accident Analysis \& Prevention, 142, 105566. https://doi.org/10.1016/j.aap.2020.105566

Lam, L. T. (2003). Factors associated with young drivers' car crash injury: comparisons among learner, provisional, and full licensees. Accident Analysis \& Prevention, 35(6), 913-920. https://doi.org/10.1016/S0001-4575(02)00099-4

Lappe, M., \& Grigo, A. (1999). How stereovision interacts with optic flow perception: neural mechanisms. Neural Networks, 12(9), 1325-1329. https://doi.org/10.1016/s0893$\underline{6080(99) 00061-1}$

Lotfi, S., Honarvar, A. R., \& Gholamzadeh, S. (2019). Analysis and identification of the hidden relationships between effective factors in the mortality rate caused by road accidents: A case study of Fars Province, Iran. Chinese Journal of Traumatology, 22(4), 233-239. https://doi.org/10.1016/j.cjtee.2018.11.004

Lučić, P., \& Teodorović, D. (2001). Bee system: Modeling combinatorial optimization transportation engineering problems by swarm intelligence. In Preprints of the TRISTAN IV triennial symposium on transportation analysis, Sao Miguel, Azores Islands, Portugal (pp. 441-445).

Lučić, P., \& Teodorović, D. (2003). Computing with bees: attacking complex transportation engineering problems. International Journal on Artificial Intelligence Tools, 12(3), 375-394. https://doi.org/10.1142/S0218213003001289

Mahmoodabadi, M.J. \& Nejadkourki, N. (2020). Optimal fuzzy adaptive robust PID control for an active suspension system, Australian Journal of Mechanical Engineering. https://doi.org/10.1080/14484846.2020.1734154 
Marković, G.Z. (2017). Revenue-driven Lightpaths Provisioning over Optical WDM Networks Using Bee Colony Optimization. International Journal of Computational Intelligence Systems, 10(1), 481-494. https://doi.org/10.2991/ijcis.2017.10.1.33

Martens, M. H., \& Brouwer, R. F. (2013). Measuring being lost in thought: An exploratory driving simulator study. Transportation Research Part F: Traffic Psychology and Behaviour, 20, 1728. https://doi.org/10.1016/j.trf.2013.04.002

Mathur, D. R. (2010). Validation of driving simulator and driver perception of vehicle mounted attenuator markings in work zones. Masters theses.

Mohammadzadeh, A., \& Kayacan, E. (2020). A novel fractional-order type-2 fuzzy control method for online frequency regulation in ac microgrid. Engineering Applications of Artificial Intelligence, 90, 103483. https://doi.org/10.1016/j.engappai.2020.103483

McCartt, A. T., Shabanova, V. I., \& Leaf, W. A. (2003). Driving experience, crashes and traffic citations of teenage beginning drivers. Accident Analysis \& Prevention, 35(3), 311-320. https://doi.org/10.1016/S0001-4575(02)00006-4

McDonald, H., Berecki-Gisolf, J., Stephan, K., \& Newstead, S. (2020). Preventing road crashes: do infringements for traffic offences have a deterrent effect amongst drivers aged 40+? An examination of administrative data from Victoria, Australia. Transportation Research Part F: Traffic Psychology and Behaviour, 69, 91-100. https://doi.org/10.1016/j.trf.2020.01.004

McGwin Jr, G., \& Brown, D. B. (1999). Characteristics of traffic crashes among young, middle-aged, and older drivers. Accident Analysis \& Prevention, 31(3), 181-198. https://doi.org/10.1016/S0001-4575(98)00061-X

Misaghi, P., \& Hassan, Y. (2005). Modeling operating speed and speed differential on two-lane rural roads. Journal of Transportation Engineering, 131(6), 408-418. https://doi.org/10.1061/(ASCE)0733-947X(2005)131:6(408)

Murphy, P., \& Morris, A. (2020). Quantifying accident risk and severity due to speed from the reaction point to the critical conflict in fatal motorcycle accidents. Accident Analysis \& Prevention, 141, 105548. https://doi.org/10.1016/j.aap.2020.105548

Nagammai, S., Latha, S., \& Varatharajan, M. (2020). Soft computing-based fuzzy integral sliding mode control: a real-time investigation on a conical tank process. Soft Computing. https://doi.org/10.1007/s00500-020-04729-7

Nath, A., Mthethwa, F., \& Saha, G. (2020). Runoff estimation using modified adaptive neuro-fuzzy inference system. Environmental Engineering Research, 25(4), 545-553. https://doi.org/10.4491/eer.2019.166

Nemet, S., Kukolj, D., Ostojic, G., Stankovski, S., \& Jovanovic, D. (2019). Aggregation framework for TSK fuzzy and association rules: interpretability improvement on a traffic accidents case. Applied Intelligence, 49(11), 3909-3922. https://doi.org/10.1007/s10489-019-01485-6

Nikolić, M., Šelmić, M., Macura, D., \& Ćalić, J. (2020). Bee Colony Optimization metaheuristic for fuzzy membership functions tuning. Expert Systems with Applications, 158, 113601, https://doi.org/10.1016/j.eswa.2020.113601

Nikolić, M., \& Teodorović, D. (2013). Transit network design by Bee Colony Optimization. Expert Systems with Applications, 40, 5945-5955. https://doi.org/10.1016/j.eswa.2013.05.002

OGRS. (2020). Law on Road Traffic Safety. Official Gazette, Republic of Serbia, 41/2009, 53/2010, $101 / 2011,32 / 2013,2 / 2018,66 / 2019$.

Ojsteršek, T. C., \& Topolšek, D. (2019). Influence of drivers' visual and cognitive attention on their perception of changes in the traffic environment. European Transport Research Review, 11(1), 1-9. https://doi.org/10.1186/s12544-019-0384-2

PAHO. (2018). Speed and road crashes. Pan American Health Organization. https://www.paho.org/sites/default/files/2018-SpeedRoadCrashes_ENGLISH_FINAL.pdf Accessed 18 March 2020.

Pešić, D., Trifunović, A., Ivković, I., Čičević, S., \& Žunjić, A. (2019). Evaluation of the effects of daytime running lights for passenger cars. Transportation Research Part F: Traffic Psychology and Behaviour, 66, 252-261. https://doi.org/10.1016/j.trf.2019.09.008 
Precup, R.E., Voisan, E.I., Petriu, E.M., Tomescu, M.L., David, R.C., Szedlak-Stinean, A.I., \& Roman, R.C. (2020). Grey Wolf Optimizer-Based Approaches to Path Planning and Fuzzy Logic-based Tracking Control for Mobile Robots. International Journal of Computers Communications \& Control, 15(3), UNSP 3844. https://doi.org/10.15837/ijccc.2020.3.3844

Road Traffic Safety Agency. (2020). On line Statistical Report on the State of Traffic Safety in the Republic of Serbia for the year 2019. Serbia. http://195.222.99.60/ibbsPublic/

Rolison, J. J., Hanoch, Y., Wood, S., \& Liu, P. J. (2014). Risk-taking differences across the adult life span: a question of age and domain. Journals of Gerontology Series B: Psychological Sciences and Social Sciences, 69(6), 870-880. https://doi.org/10.1093/geronb/gbt081

Rolison, J. J., Regev, S., Moutari, S., \& Feeney, A. (2018). What are the factors that contribute to road accidents? An assessment of law enforcement views, ordinary drivers' opinions, and road accident records. Accident Analysis \& Prevention, 115, 11-24. https://doi.org/10.1016/j.aap.2018.02.025

Rudin-Brown, C. M. (2004). Vehicle height affects drivers' speed perception: Implications for rollover risk. Transportation Research Record, 1899(1), 84-89. https://doi.org/10.3141/1899$\underline{11}$

Saluäär, D. (2000). Driving simulators as a means of studying the interaction between driver and vehicle. Internal Volvo Report, ER-520034

Schlögl, M. (2020). A multivariate analysis of environmental effects on road accident occurrence using a balanced bagging approach. Accident Analysis \& Prevention, 136, 105398. https://doi.org/10.1016/j.aap.2019.105398

Sun, R., Zhuang, X., Wu, C., Zhao, G., \& Zhang, K. (2015). The estimation of vehicle speed and stopping distance by pedestrians crossing streets in a naturalistic traffic environment. Transportation Research Part F: Traffic Psychology and Behaviour, 30, 97-106. https://doi.org/10.1016/j.trf.2015.02.002

Thakur, G.S. (2014). Fuzzy Soft Traffic Accident Alert Model. National Academy Science LettersIndia, 37(3), 261-268. https://doi.org/10.1007/s40009-014-0235-6

Tremante, P., Yen, K., \& Brea, E. (2019). Tuning of the membership functions of a fuzzy control system using pattern search optimization method. Journal of Intelligent \& Fuzzy Systems, 37(3), 3763-3776. https://doi.org/10.3233/jifs-190003

Trifunović, A. V., Čičević, S. J., Lazarević, D. M., Dragović, M. S., Vidović, N. D., Mošić, M. R., \& Otat, O. V. (2019). Perception of 3D virtual road markings: Based on estimation of vehicle speed. FME Transactions, 47(2), 360-369. https://doi.org/10.5937/fmet1902360T

Troscianko, T., Wright, P., \& Wright, D. (1999). Perceived speed of urban traffic. Perception ECVP abstract, 28, 1_suppl: 60-60.

Wang, Y. C., Foss, R. D., O'Brien, N. P., Goodwin, A. H., \& Harrell, S. (2020). Effects of an advanced driver training program on young traffic offenders' subsequent crash experience. Safety Science, 130, 104891. https://doi.org/10.1016/j.ssci.2020.104891

Wang, L., \& Mendel, J. (1992). Generating fuzzy rules by learning from examples. IEEE Transactions on Systems, Man and Cybernetics, 22(6), 1414-1427. https://doi.org/10.1109/21.199466

Weber, S., Tschech, K., Ernstberger, K., Labenski, V., \& Blum, K. (2018). Different types of distraction causing accidents. Presentation at the DDI.

WHO. (2018). The Global Status Report on Road Safety 2018. World Health Organization, Geneva, Switzerland. https://www.who.int/violence injury prevention/road safety status/2018/en/ Accessed 12 March 2020.

Wu, C., Yu, D., Doherty, A., Zhang, T., Kust, L., \& Luo, G. (2017). An investigation of perceived vehicle speed from a driver's perspective. PLoS one, 12(10). https://doi.org/10.1371/journal.pone.0185347

Wynne, R. A., Beanland, V., \& Salmon, P. M. (2019). Systematic review of driving simulator validation studies. Safety science, 117, 138-151. https://doi.org/10.1016/j.ssci.2019.04.004 
Xiong, X., Wang, M., Cai, Y., Chen, L., Farah, H., Hagenzieker, M. (2019). A forward collision avoidance algorithm based on driver braking behavior. Accident Analysis and Prevention, 129, 30-43, https://doi.org/10.1016/j.aap.2019.05.004

Yan, X., Abdel-Aty, M., Radwan, E., Wang, X., \& Chilakapati, P. (2008). Validating a driving simulator using surrogate safety measures. Accident Analysis \& Prevention, 40(1), 274-288. https://doi.org/10.1016/j.aap.2007.06.007

Yazid, E., Garratt, M., \& Santoso, F. (2019). Control position of a quadcopter drone using evolutionary algorithms optimized self-tuning 1st-order Takagi-Sugeno-Kang-type fuzzy logic controller. Applied Soft Computing, 78, 373-392. https://doi.org/10.1016/j.asoc.2019.02.023

Zheng, Z., Du, Z., Xiang, Q., \& Chen, G. (2018). Influence of multiscale visual information on driver's perceived speed in highway tunnels. Advances in Mechanical Engineering, 10(12), 112. https://doi.org/10.1177/1687814018818961

Zorić, N. D., Tomović, A. M., Obradović, A. M., Radulović, R. D., \& Petrović, G. R. (2019). Active vibration control of smart composite plates using optimized self-tuning fuzzy logic controller with optimization of placement, sizing and orientation of PFRC actuators. Journal of Sound and Vibration, 456, 173-198. https://doi.org/10.1016/j.jsv.2019.05.035 


\section{Figures}

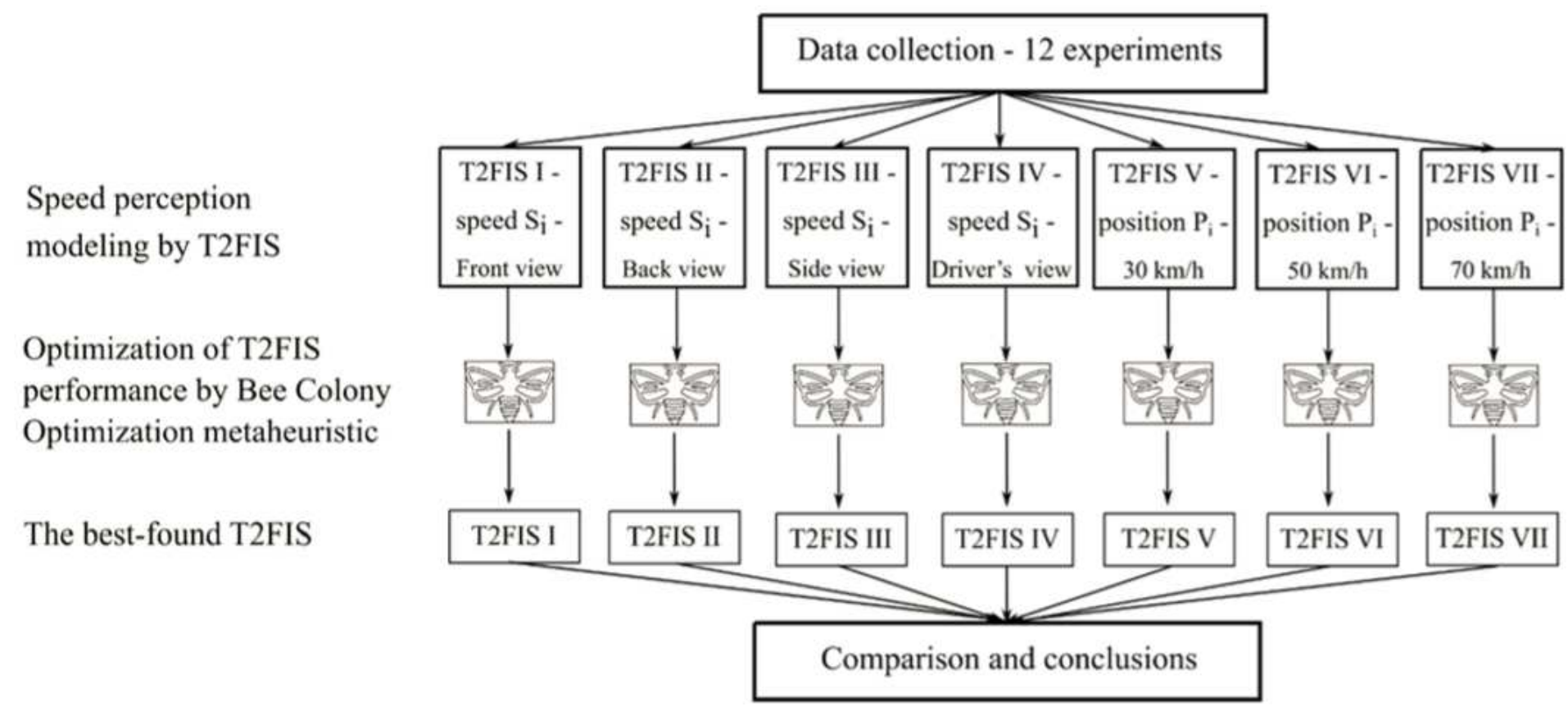

Figure 1

A configuration of the research: the parameter $\mathrm{Si}(\mathrm{i}=1,3)$ takes the following values: $\mathrm{S} 1=30 \mathrm{~km} / \mathrm{h}, \mathrm{S} 2=$ $50 \mathrm{~km} / \mathrm{h}$, and $\mathrm{S} 3=70 \mathrm{~km} / \mathrm{h}$; the parameter $\mathrm{Pj}(\mathrm{j}=1,4)$ takes the following values: $\mathrm{P} 1=$ Front view, $\mathrm{P} 2=$ Rear view, P3 = Side view, and P4 = Driver's seat perspective

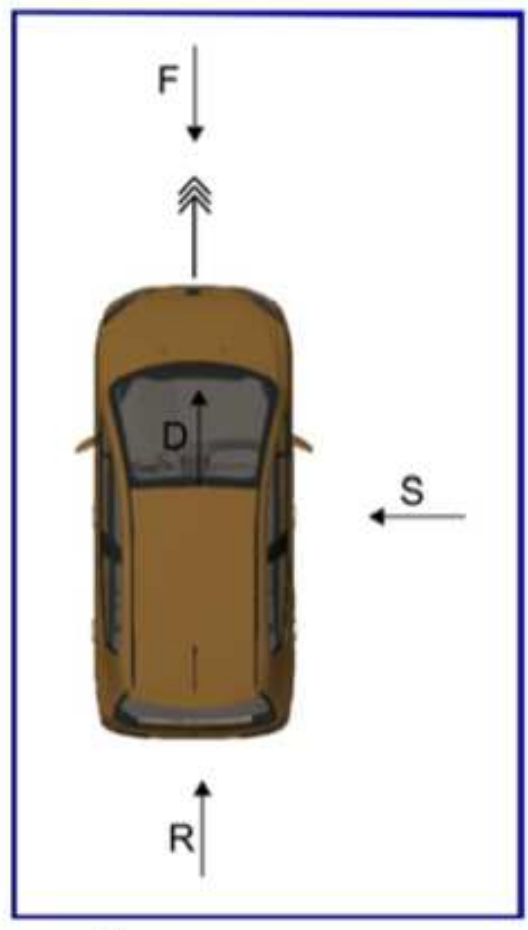

A)

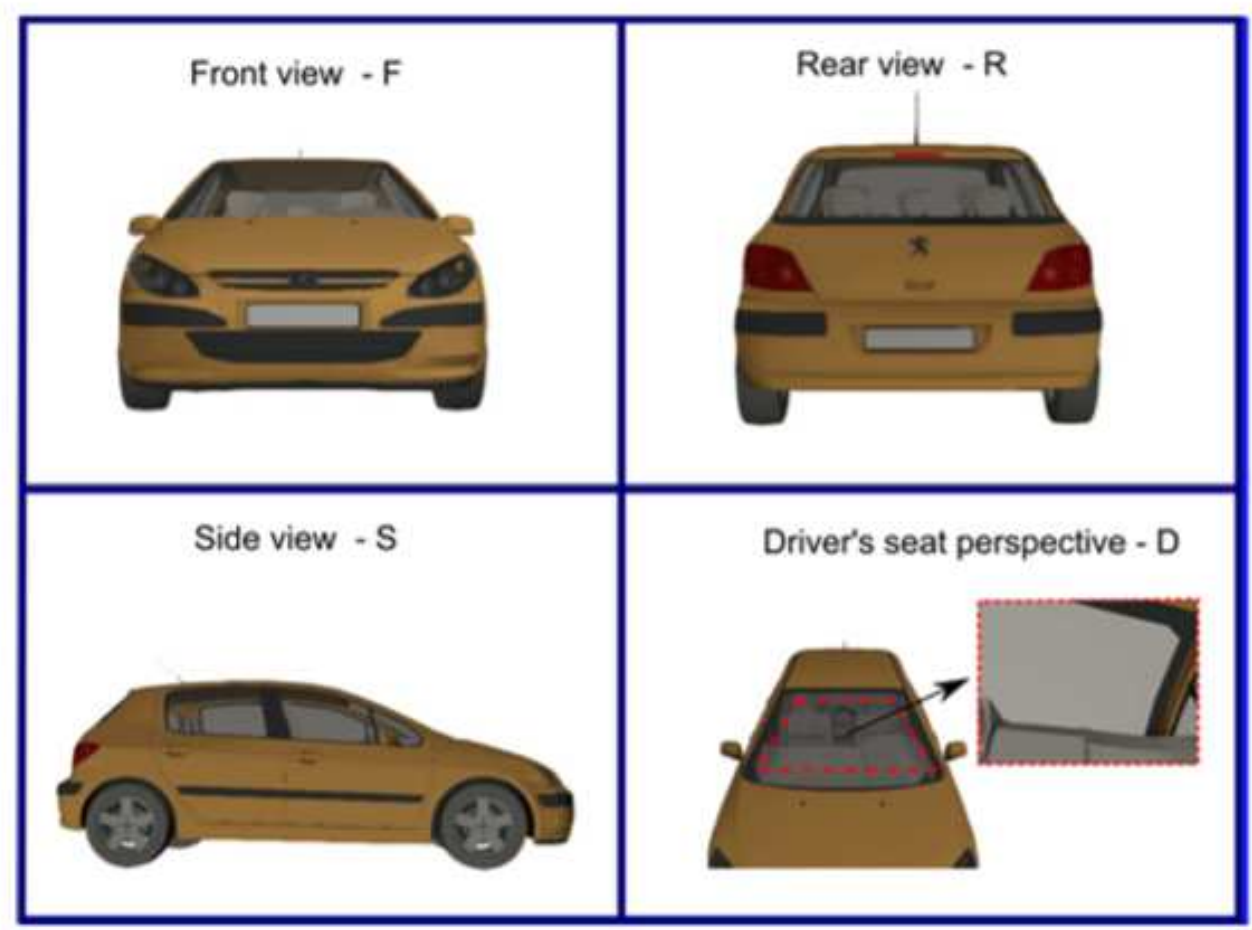

B)

Figure 2 
Presentation of vehicle speed perception for four different perspectives A) four different perspectives B) appearance of the vehicle from the perspective of the respondents

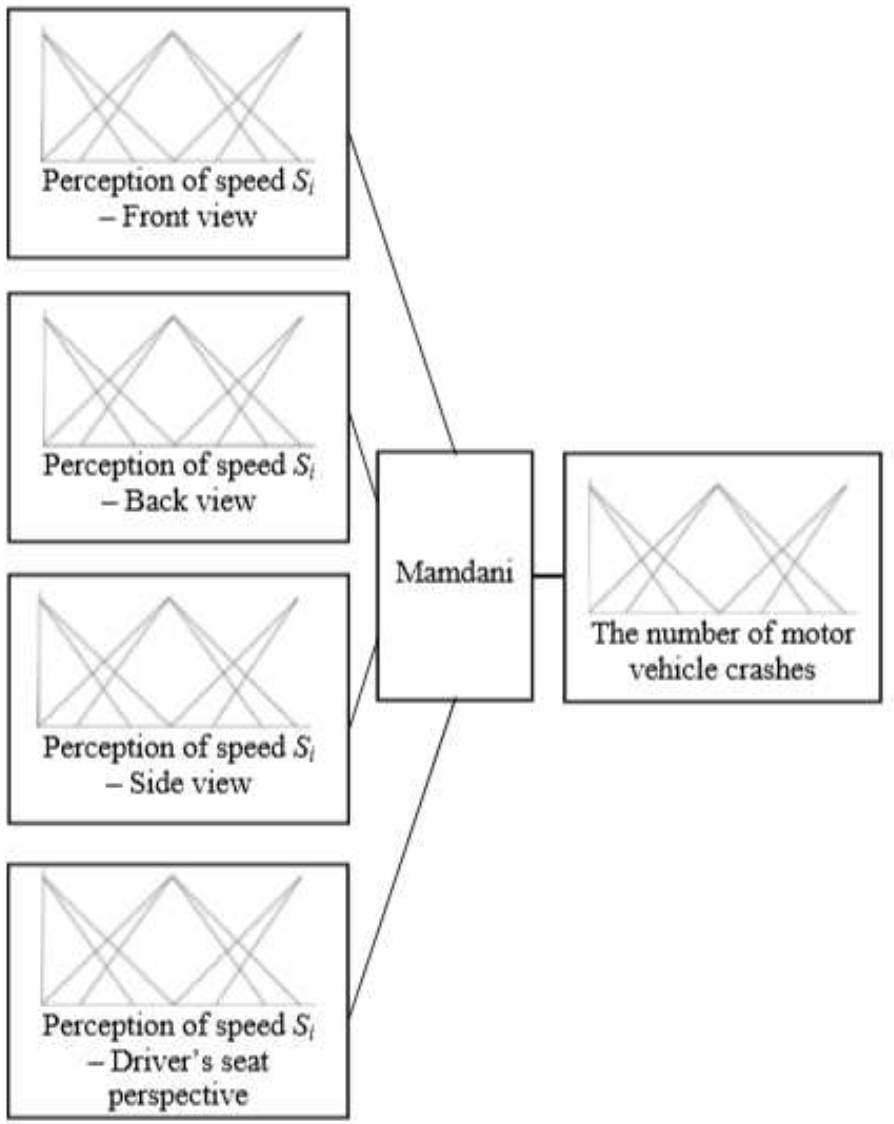

(a)

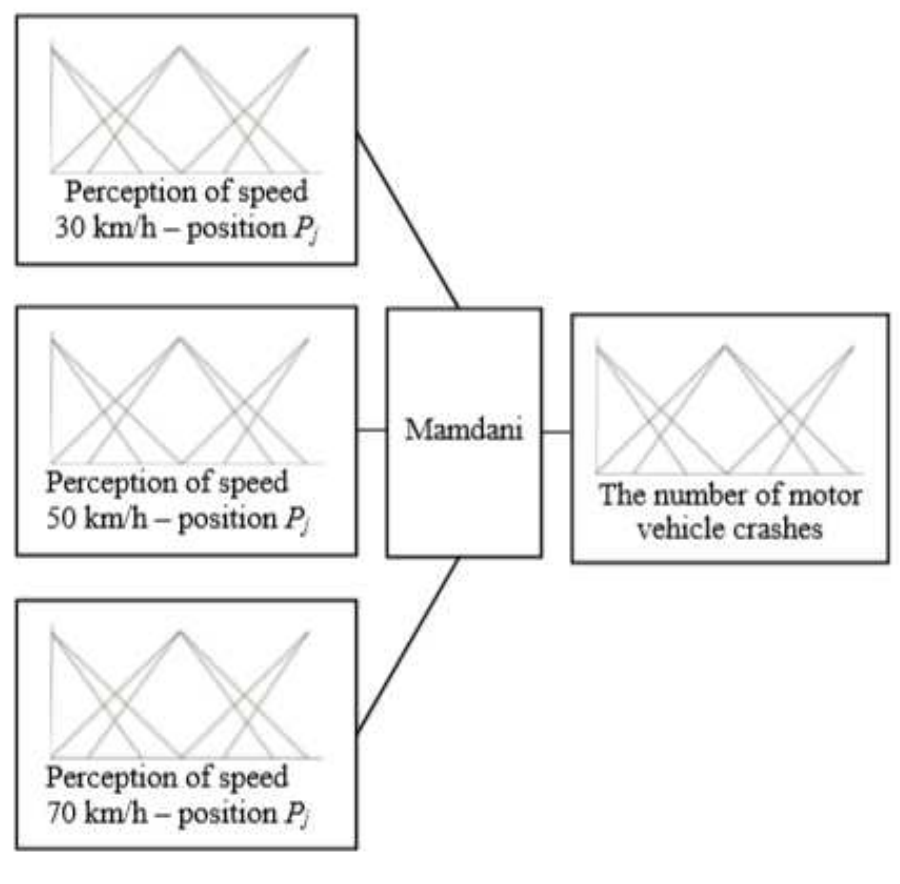

(b)

\section{Figure 3}

The proposed model of speed perception: (a) the parameter $\mathrm{Si}(\mathrm{i}=1,3)$ takes the following values: $\mathrm{S} 1=30$ $\mathrm{km} / \mathrm{h}, \mathrm{S} 2=50 \mathrm{~km} / \mathrm{h}$, and S3 $=70 \mathrm{~km} / \mathrm{h}$; (b) the parameter $P \mathrm{P}(\mathrm{j}=1,4)$ takes the following values: $\mathrm{P} 1=$ Front view, $\mathrm{P} 2=$ Rear view, $\mathrm{P} 3=$ Side view, and P4 = Driver's seat perspective 


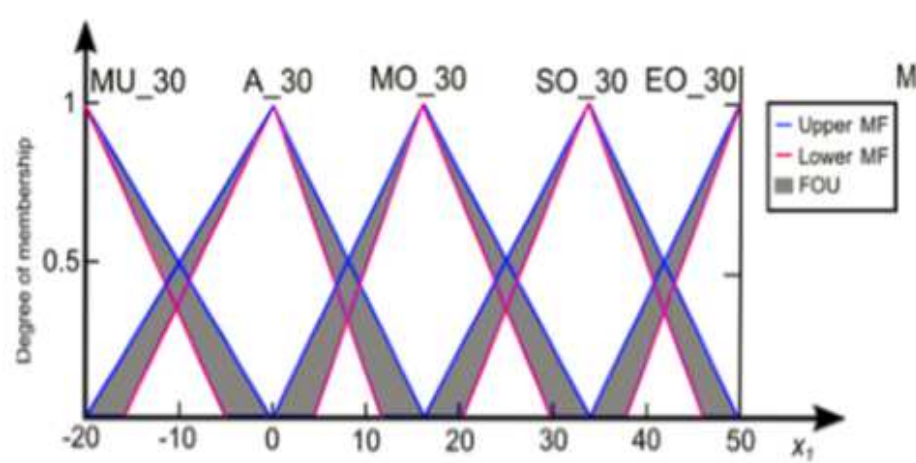

a)

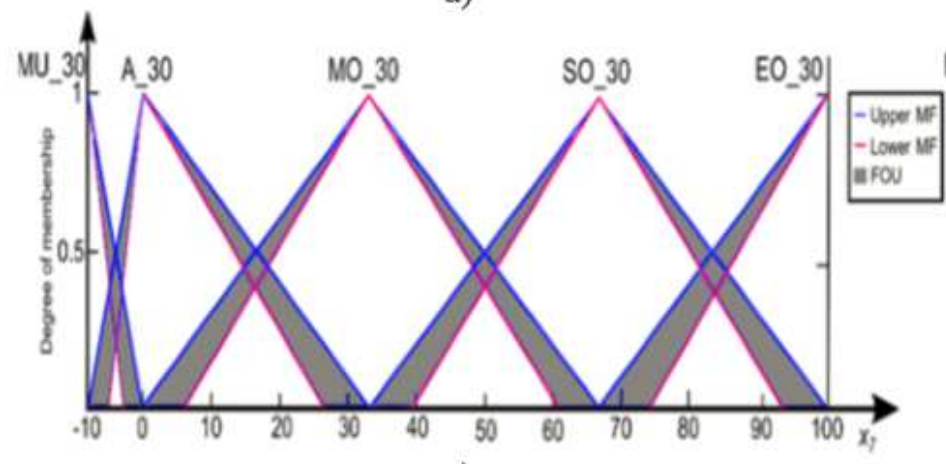

c)

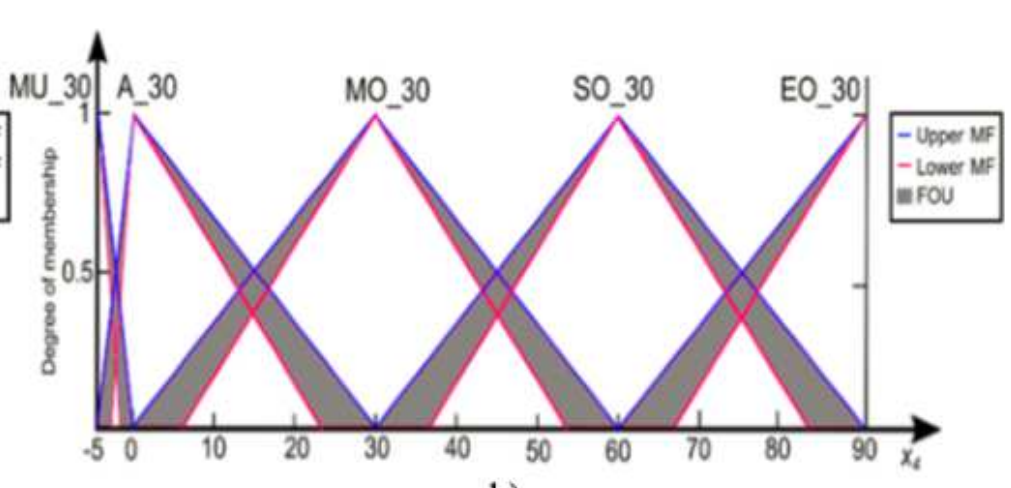

b)

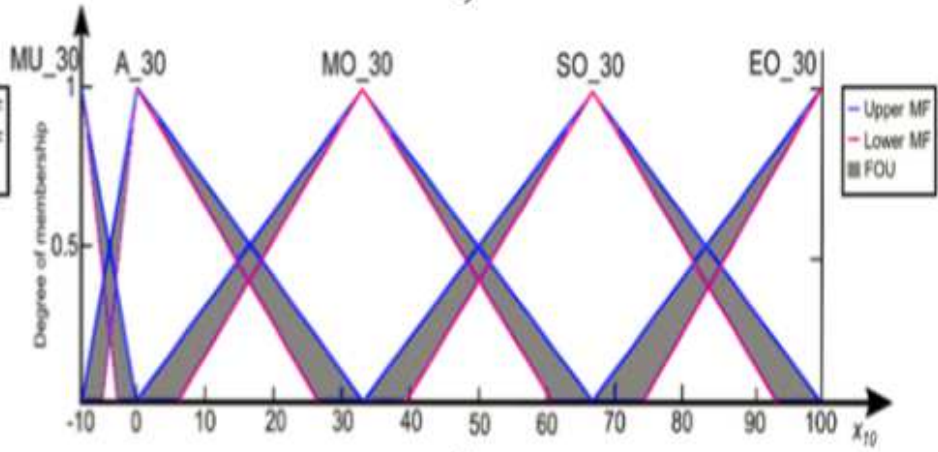

d)

\section{Figure 4}

nput variables for T2FIS_30; Part a) variable $x 1$ - Front view: $30 \mathrm{~km} / \mathrm{h}$; Part b) variable $\mathrm{x} 4$ - Rear view: $30 \mathrm{~km} / \mathrm{h}$; Part c) variable $x 7$ - Side view: $30 \mathrm{~km} / \mathrm{h}$; Part d) variable $x 10$ - Driver's perspective: $30 \mathrm{~km} / \mathrm{h}$

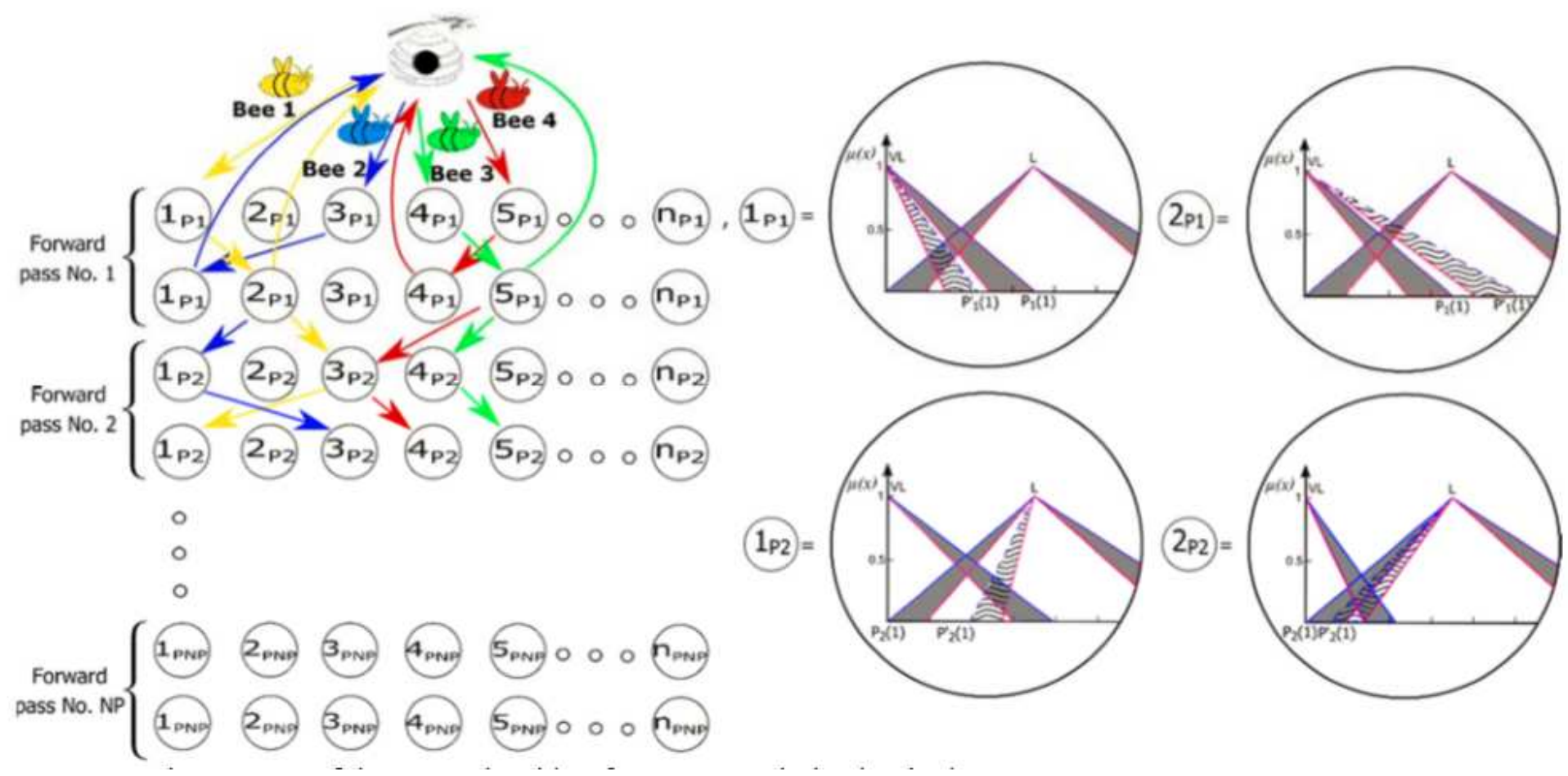

Figure 5

The concept of the BCO algorithm for T2FIS optimization in the case B=4, NC=2. 


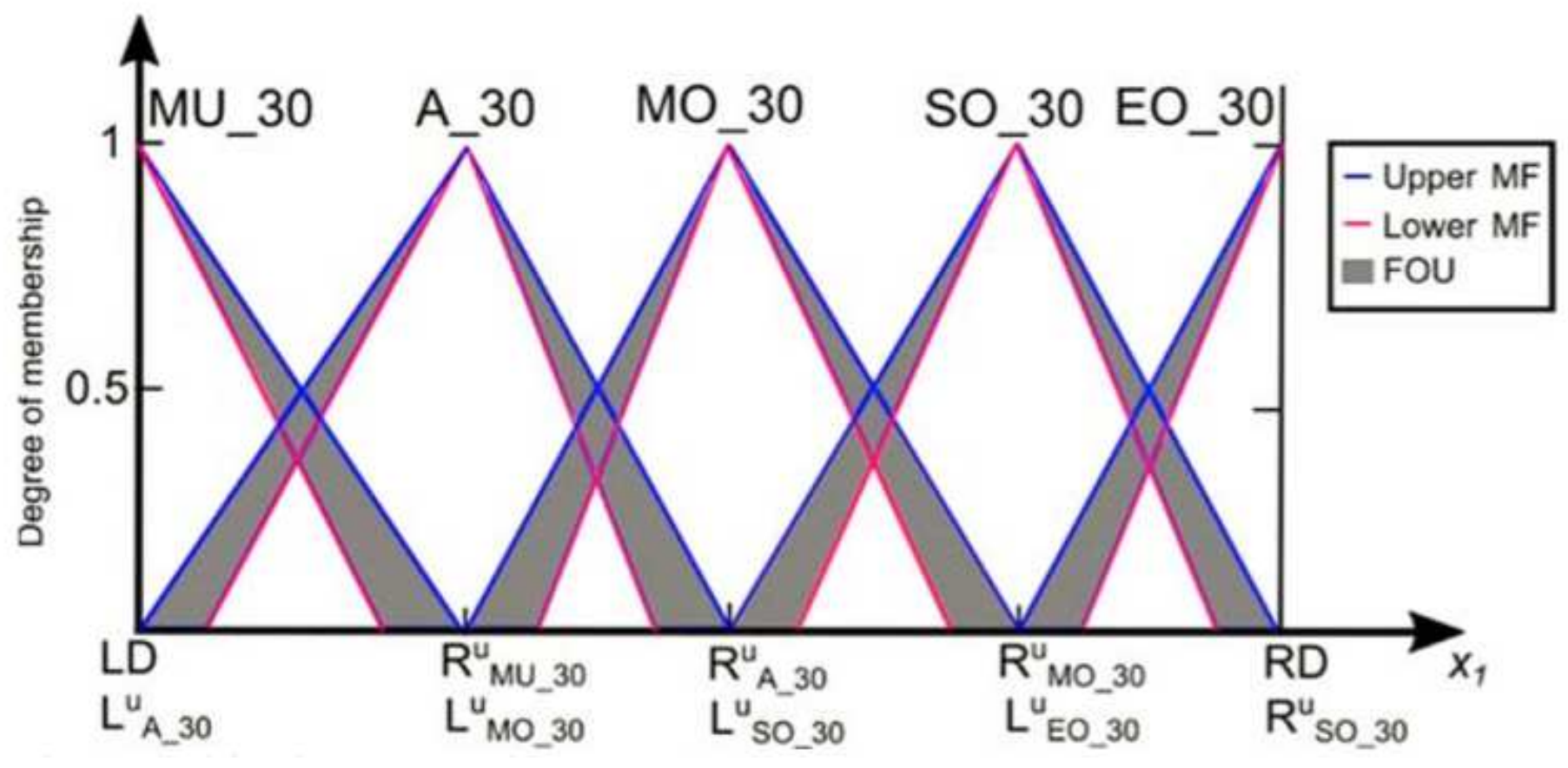

Figure 6

A part of the notation used in the constraints

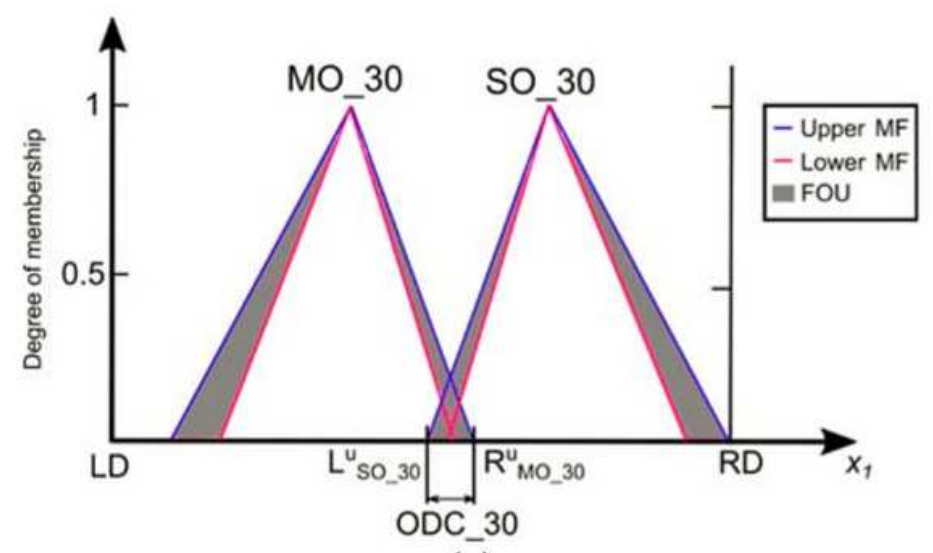

(a)

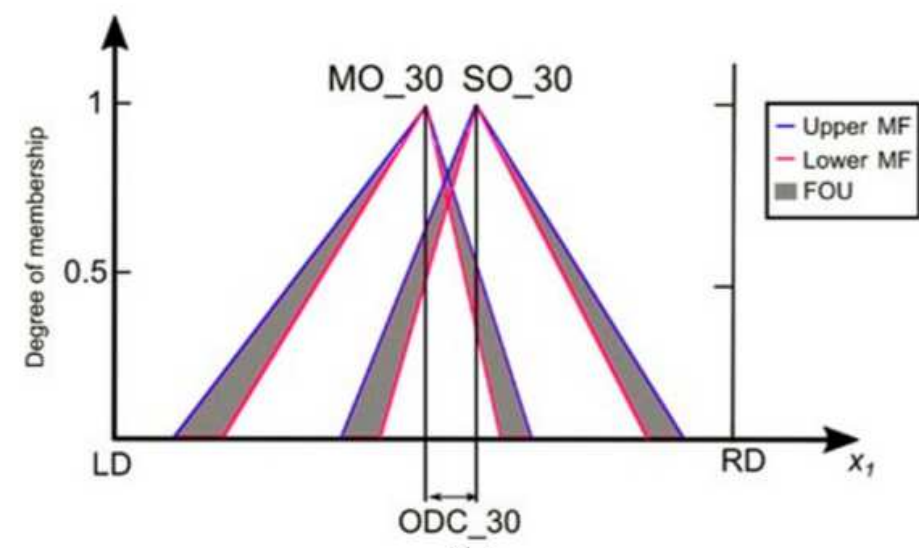

(b)

Figure 7

A presentation of Overlapping and Distance Constant (ODC): (a) the minimum allowed overlapping in the proposed algorithm; (b) the minimum allowed distance between two membership functions for the points with the maximum degree $(\mu(x)=1)$ 


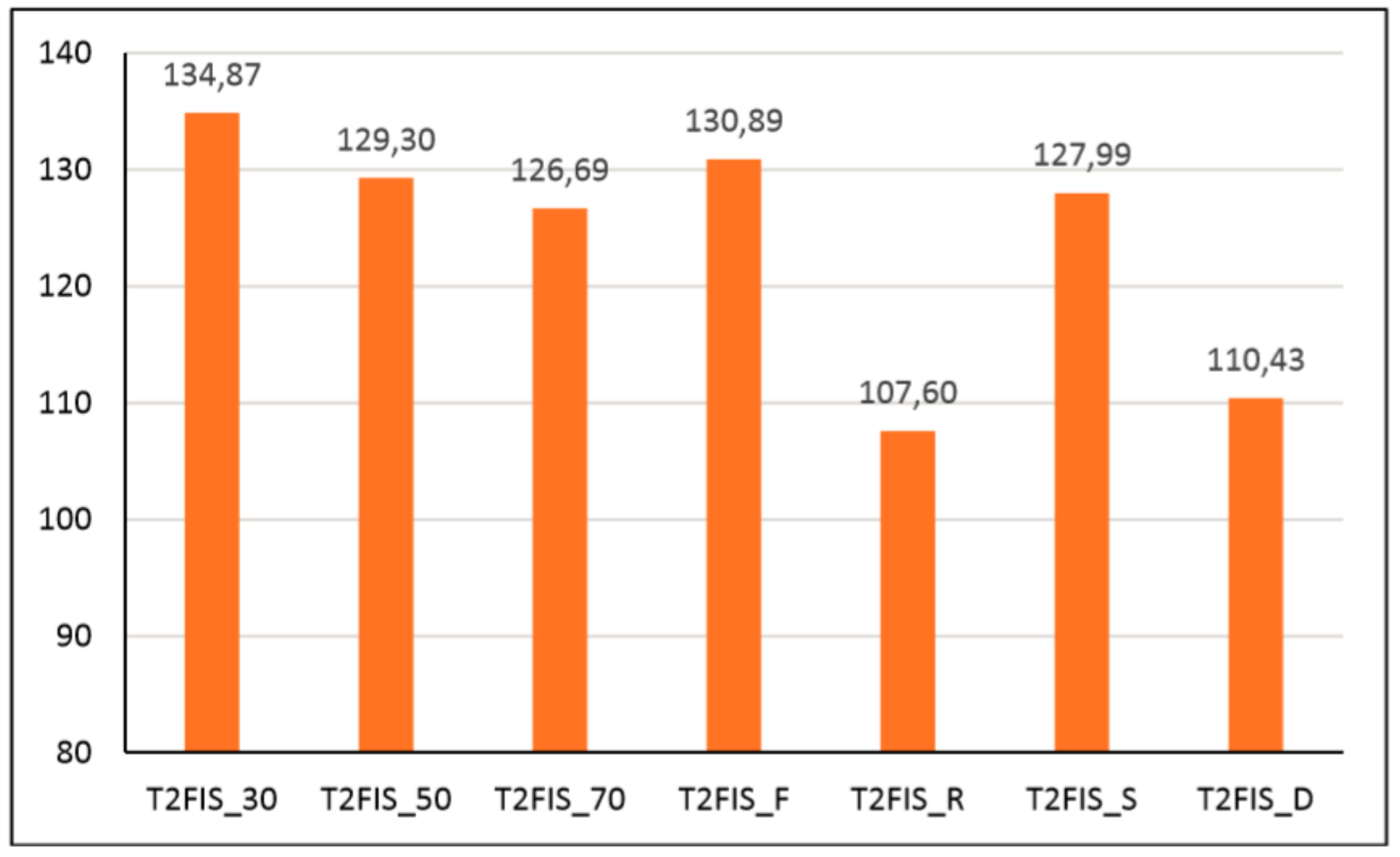

Figure 8

The initial results of testing different T2FIS structures - the obtained CD values 


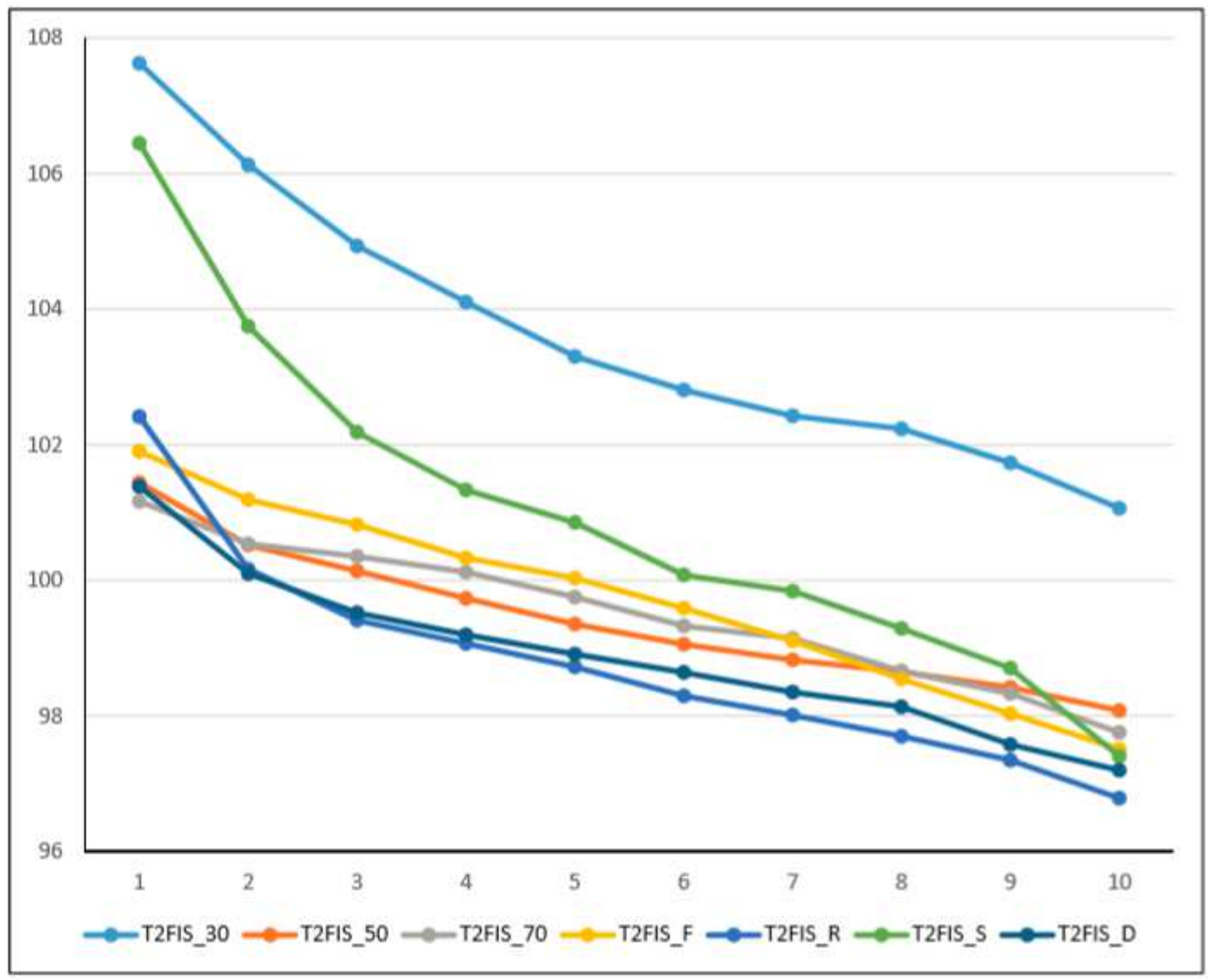

Figure 9

The results of different T2FIS structures optimization - mean values of 8 experiments 


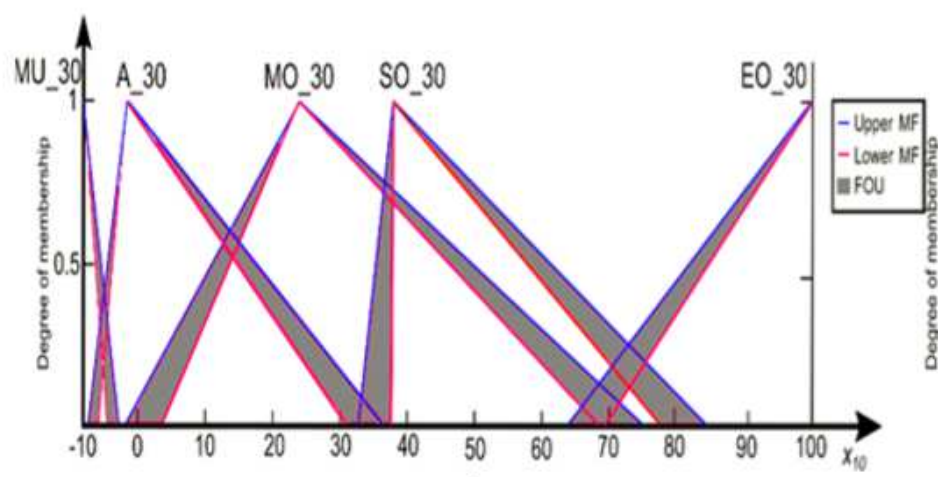

a)

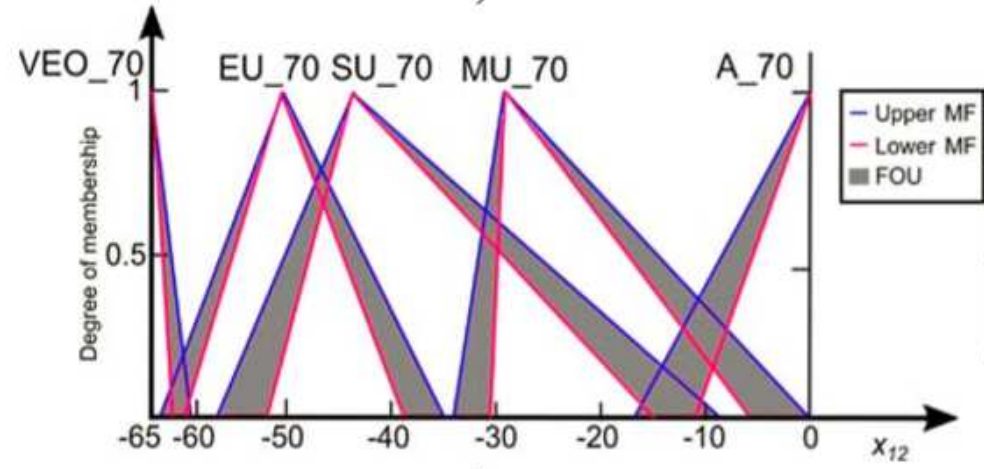

c)

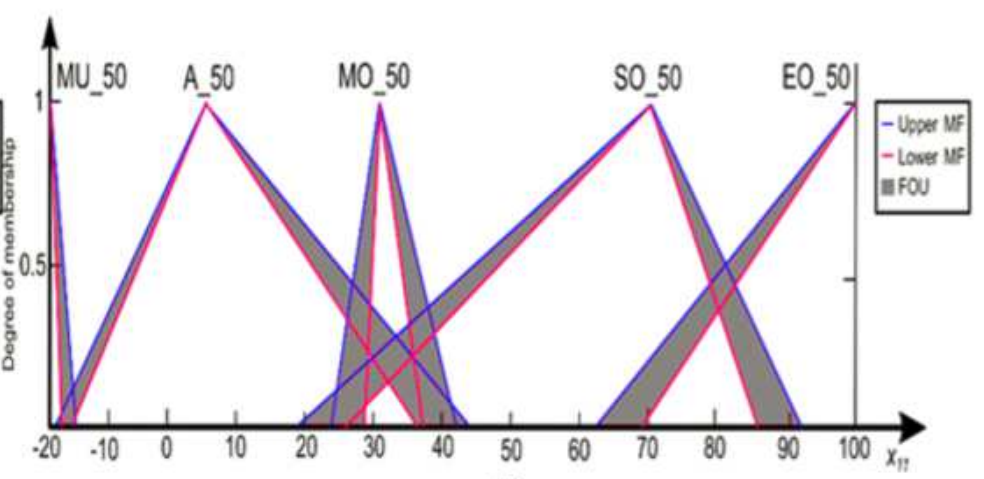

b)

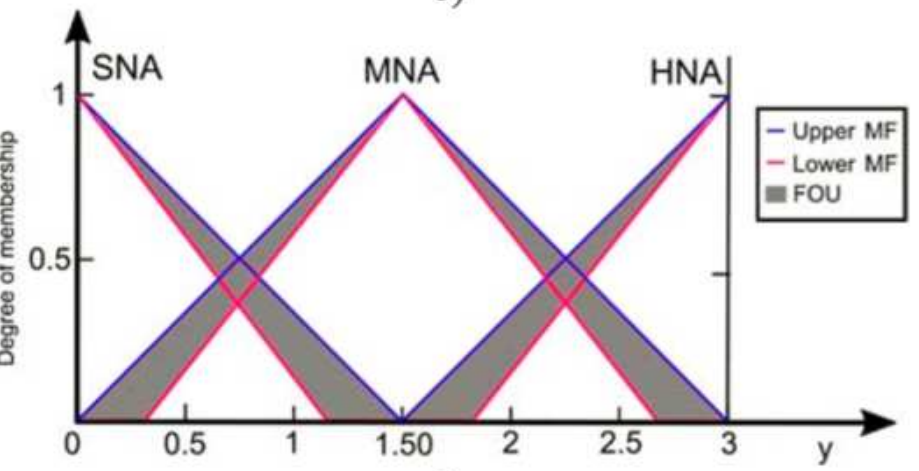

d)

Figure 10

Input and output variables for T2FIS_D after optimization procedure; Part a) variable x10 - Driver's perspective: $30 \mathrm{~km} / \mathrm{h}$; Part b) variable x11 - Driver's perspective: $50 \mathrm{~km} / \mathrm{h}$; Part c) variable x12 - Driver's perspective: $70 \mathrm{~km} / \mathrm{h}$; Part d) variable $\mathrm{y}$ - The number of motor vehicle crashes 